\title{
Report on Reactor Physics Assessment of Candidate Accident Tolerant Fuel Cladding Materials in LWRs
}

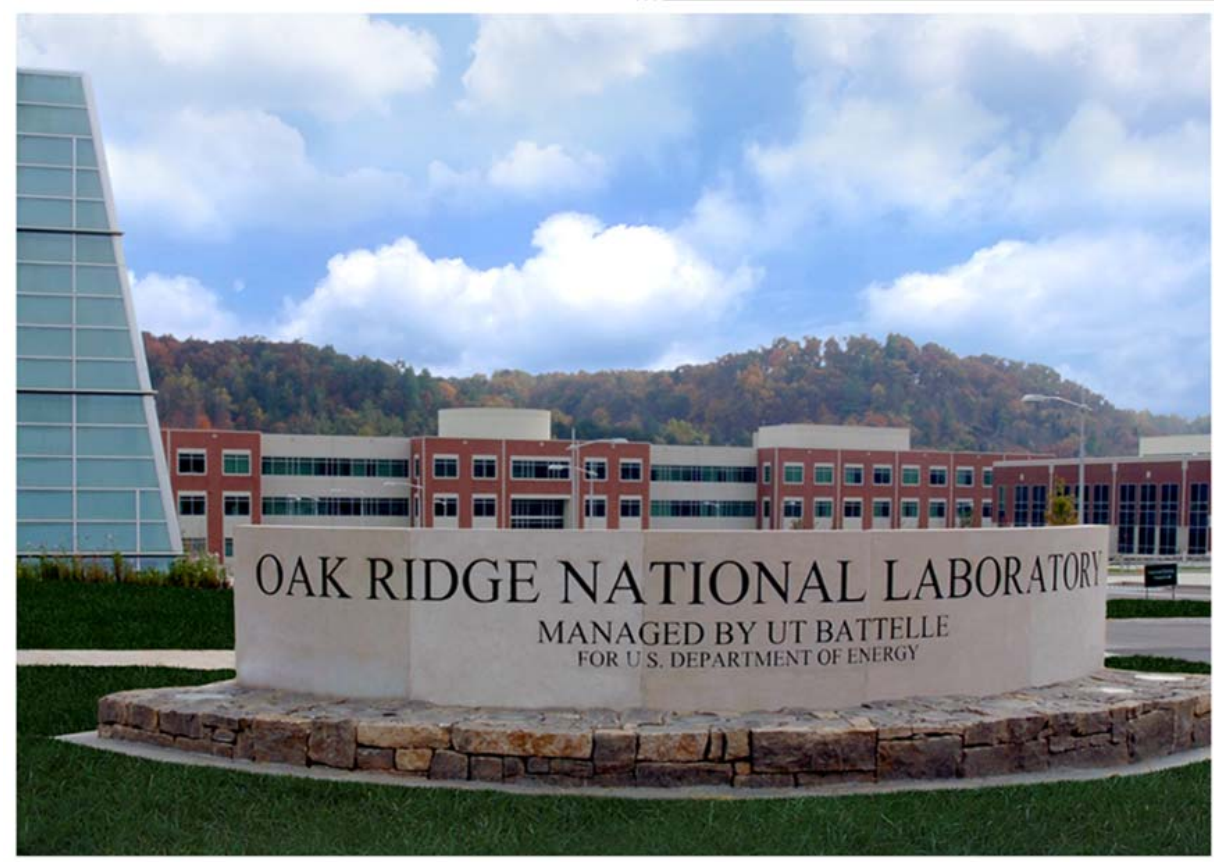
J. J. Powers
N. M. George
G. I. Maldonado
A. Worrall

August 28, 2015 


\title{
DOCUMENT AVAILABILITY
}

Reports produced after January 1, 1996, are generally available free via US Department of Energy (DOE) SciTech Connect.

Website http://www.osti.gov/scitech/

Reports produced before January 1, 1996, may be purchased by members of the public from the following source:

\author{
National Technical Information Service \\ 5285 Port Royal Road \\ Springfield, VA 22161 \\ Telephone 703-605-6000 (1-800-553-6847) \\ TDD 703-487-4639 \\ Fax 703-605-6900 \\ E-mail info@ntis.gov \\ Website http://www.ntis.gov/help/ordermethods.aspx
}

Reports are available to DOE employees, DOE contractors, Energy Technology Data Exchange representatives, and International Nuclear Information System representatives from the following source:

Office of Scientific and Technical Information

PO Box 62

Oak Ridge, TN 37831

Telephone 865-576-8401

Fax 865-576-5728

E-mail reports@osti.gov

Website http://www.osti.gov/contact.html

This report was prepared as an account of work sponsored by an agency of the United States Government. Neither the United States Government nor any agency thereof, nor any of their employees, makes any warranty, express or implied, or assumes any legal liability or responsibility for the accuracy, completeness, or usefulness of any information, apparatus, product, or process disclosed, or represents that its use would not infringe privately owned rights. Reference herein to any specific commercial product, process, or service by trade name, trademark, manufacturer, or otherwise, does not necessarily constitute or imply its endorsement, recommendation, or favoring by the United States Government or any agency thereof. The views and opinions of authors expressed herein do not necessarily state or reflect those of the United States Government or any agency thereof. 


\title{
REPORT ON REACTOR PHYSICS ASSESSMENT OF CANDIDATE ACCIDENT TOLERANT FUEL CLADDING MATERIALS IN LWRs
}

\author{
J. J. Powers \\ N. M. George \\ G. I. Maldonado \\ A. Worrall
}

Date Published: August 28, 2015

Prepared by

OAK RIDGE NATIONAL LABORATORY

Oak Ridge, TN 37831-6283

managed by

UT-BATTELLE, LLC

for the

US DEPARTMENT OF ENERGY

under contract DE-AC05-00OR22725 



\section{CONTENTS}

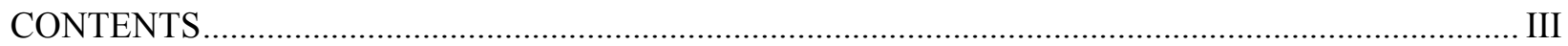

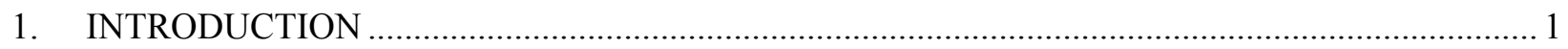

2. NEUTRONICS IMPACTS OF ATF CLADDING MATERIALS................................................... 3

2.1 SUMMARY ASSESSMENT OF ATF CLADDING MATERIALS IN PWRS ...................... 4

3. BWR LATTICE PHYSICS ASSESSMENT OF ATF CLADDING MATERIALS.......................... 7

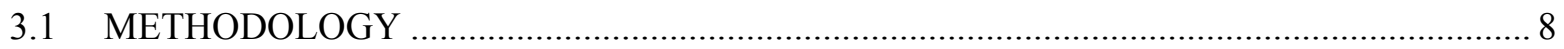

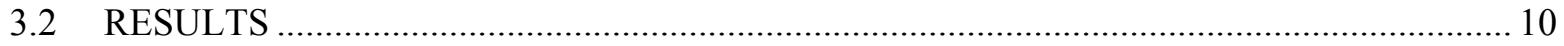

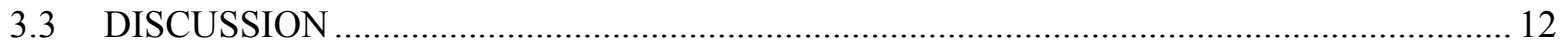

4. BWR CORE-LEVEL ASSESSMENT OF ATF CLADDING MATERIALS …............................ 15

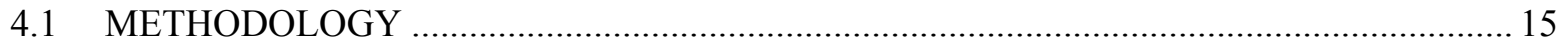

4.1.1 Lattice Physics Cross Section Generation Models................................................ 15

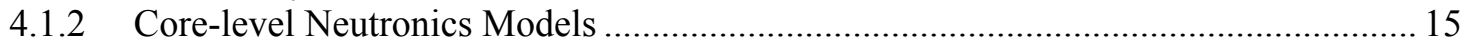

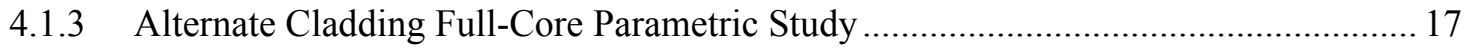

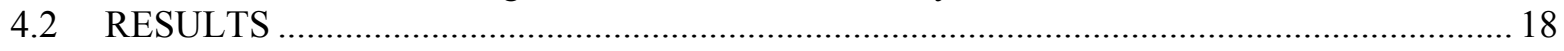

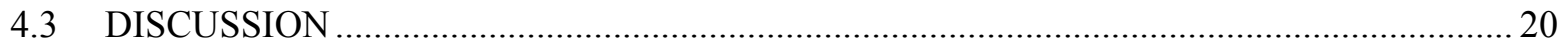

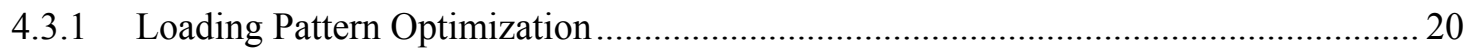

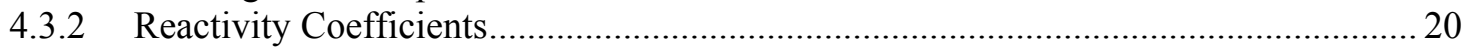

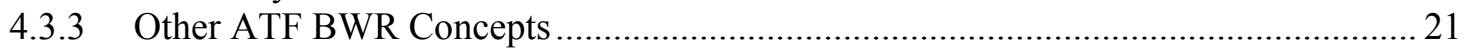

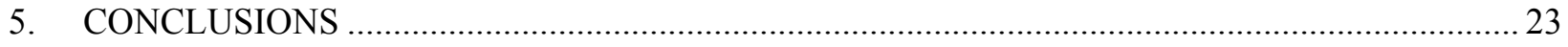

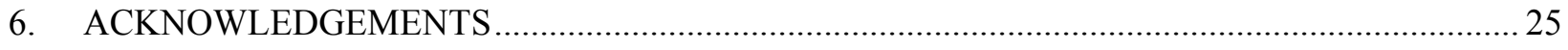

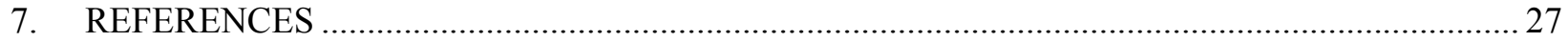




\section{LIST OF FIGURES}

Fig. 1. Macroscopic neutron absorption cross sections for several clad material options.................... 4

Fig. 2. Fuel parameter combinations that match cycle length of PWR with Zircaloy cladding. ............ 6

Fig. 3. Illustration of a $10 \times 10$ BWR lattice modeled with TRITON. ............................................. 7

Fig. 4. Allocation of lattices within BWR fuel bundle. ................................................................. 8

Fig. 5. Representative GE BWR quarter core exposure map for PB2C17 [27] .............................. 9

Fig. 6. Relative axial power from PB2C1 TIP data [28] ........................................................... 9

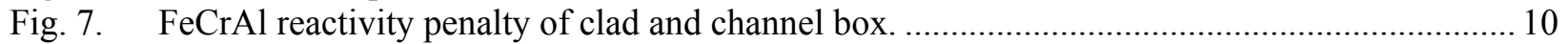

Fig. 8. EOC reactivity values with respect to fuel design changes in FeCrAl loaded bundles............ 11

Fig. 9. Fuel parameters required for $\mathrm{FeCrAl}$ to match the Zircaloy core lifetime............................. 12

Fig. 10. a. BOC bundle exposures in BWR core; and b. Hot axial power profile of DOM region. ........ 16

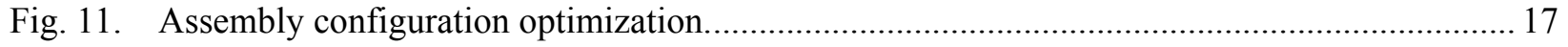

Fig. 12. Full-core Zircaloy base case depletion. ............................................................................ 18

Fig. 13. Full-core FeCrAl designs matching Zircaloy base case cycle length..................................... 19

Fig. 14. Parametric evaluation of lattice physics and full-core models. .............................................. 20 


\section{LIST OF TABLES}

Table 1. Summary of relevant data for key cladding material options ................................................. 4

Table 2. Fuel parameter combinations that match cycle length of PWR with Zircaloy cladding............... 5

Table 3. Fuel specifications for ORNL PWR ATF analyses ............................................................... 6

Table 4. FeCrAl fuel parameter combinations that match BWR cycle length of Zircaloy ........................ 12

Table 5. Specifications for full-core BWR Zircaloy reference case ...................................................... 18

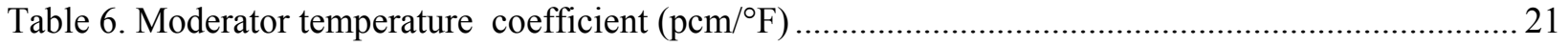

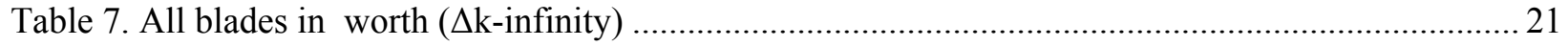

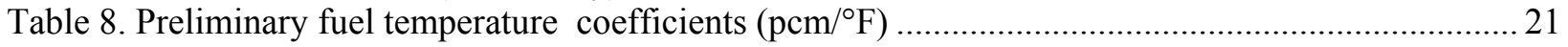




\section{ACRONYMS}

AOO

ATF

BDBA

BOC

BOL

BWR

DBA

DOE-NE

DOM

EFPD

EOC

EOL

FCM

FCRD

FeCrAl

FP

FTC

GWd/MTU

GWd/tHM

$\mathrm{HM}$

HT

LWR

MOC

MOL

MTC

$\mathrm{kW} / \mathrm{L}$

MWd/tHM

NAT

NO

ORNL

$\mathrm{P} / \mathrm{D}$

PSZ

PWR

$\mathrm{SiC}$

TIP

VAN anticipated operational occurrences

accident-tolerant fuel

beyond-design-basis accident

beginning of cycle

beginning of life

boiling water reactor

design basis accident

US Department of Energy Office of Nuclear Energy

dominant

effective full power day

end of cycle

end of life

fully ceramic microencapsulated

Fuel Cycle Research and Development

iron-chromium-aluminum

fission product

fuel temperature coefficient

gigawatt-days per metric ton of uranium

gigawatt-days/metric ton of heavy metal

heavy metal

high temperature

light water reactor

middle of cycle

middle of life

moderator temperature coefficient

kilowatts per liter (power density)

megawatt days per ton of heavy metal

natural enriched

normal operation

Oak Ridge National Laboratory

pitch-to-diameter

power-shaping zone

pressurized water reactor

silicon carbide

traversing-in-core probe

vanished 


\section{INTRODUCTION}

The US Department of Energy Office of Nuclear Energy (DOE-NE) Fuel Cycle Research and Development (FCRD) Advanced Fuels Campaign is developing enhanced accident tolerant fuel (ATF) concepts to replace the standard urania fuel in zirconium alloy cladding $\left(\mathrm{UO}_{2} /\right.$ Zircaloy) system used in existing light water reactors (LWRs) [1-3]. Candidate ATFs should improve performance during beyond design basis accidents (BDBAs) by increasing the amount of time available for operators to take mitigation actions, reducing the rate and/or extent of heat and hydrogen production during hightemperature steam oxidation, or reducing severe accident consequences by enhancing fission product (FP) retention within the fuel. Proposed ATF concepts require analysis to demonstrate that they maintain adequate performance during normal operation and anticipated transients while achieving worthwhile performance improvements in severe accident scenarios [4].

All proposed ATF concepts seek to accomplish some portion of the same overall goals: increased time for mitigation actions during severe accidents, reduced high-temperature steam oxidation rates, and/or enhanced FP retention. Numerous approaches have been developed to accomplish one or more of these objectives. Two basic pathways involve (1) changing the cladding to enhance performance during severe accidents, and/or (2) changing the fuel to either directly improve performance or overcome obstacles introduced by changing the cladding material. Possible cladding changes include coating the standard Zircaloy cladding with a thin ceramic or metallic layer to decrease oxidation rates or changing the cladding material entirely to an alternate material (e.g., iron-based alloys or ceramic composites). Modifications to the fuel could include changes to $\mathrm{UO}_{2}$ to improve performance (e.g., adding dopants to increase the thermal conductivity), changing the material to increase the heavy metal (HM) loading density (e.g., $\mathrm{UN}$ or $\mathrm{U}_{2} \mathrm{Si}_{3}$ ) to offset other penalties, or changing the material and/or form entirely (e.g., to fully ceramic microencapsulated [FCM] fuel) to enhance FP retention. These fuel and cladding concepts offer different levels of performance improvements and would require different amounts of development time before commercial deployment.

This work focuses on ATF concepts being researched at Oak Ridge National Laboratory (ORNL), expanding on previous studies of using alternate cladding materials in pressurized water reactors (PWRs). The neutronic performance of two leading alternate cladding materials were assessed in boiling water reactors (BWRs): iron-chromium-aluminum ( $\mathrm{FeCrAl}$ ) cladding, and silicon carbide ( $\mathrm{SiC}$ )-based composite cladding. This report fulfills ORNL Milestone M3FT-15OR0202332 within the fiscal year 2015 (FY15) 


\section{NEUTRONICS IMPACTS OF ATF CLADDING MATERIALS}

While numerous ATF cladding materials have been proposed, this work focuses on comparing FeCrAl and $\mathrm{SiC}$ with the reference $\mathrm{UO}_{2} /$ Zircaloy system using depletion calculation results including fuel parameter combinations needed to maintain cycle length, spectral analyses, and reactivity coefficients.

Early neutronics analyses of PWR ATF cladding concepts [5,6] included SiC and two types of iron-based alloys: austenitic stainless steels and ferritic alloys. The $\mathrm{SiC}$ cladding material was based on a $\mathrm{SiC} / \mathrm{SiC}$ composite ( $\mathrm{SiC}$ fibers embedded in an $\mathrm{SiC}$ matrix) [7] and represents a range of $\mathrm{SiC}$ concepts investigated for use in LWRs [8-10]. Austenitic stainless steel type 310 (310SS), which is included in these analyses due to its wide consideration by other organizations, contains more chromium ( $\mathrm{Cr}$ ) and nickel (Ni) than 304SS and forms a protective $\mathrm{Cr}_{2} \mathrm{O}_{3}$ scale in $\mathrm{HT}$ steam [3]. The ferritic $\mathrm{FeCrAl}$ alloys contain aluminum and form an even more protective $\mathrm{Al}_{2} \mathrm{O}_{3}$ scale in HT steam [11]. A generic FeCrAl alloy (labeled simply as $\mathrm{FeCrAl}$ ) was the main analysis example; early analyses also included a specific APMT ${ }^{\mathrm{TM}}$ alloy [12] that exhibited very similar neutronic performance to generic FeCrAl. Zircaloy and historic 304SS cladding materials were also analyzed as reference points for comparisons. Zircaloy represents zirconium alloys used as LWR cladding throughout the world. The 304SS represents generic $18 \mathrm{Cr}-8 \mathrm{Ni}$ type austenitic stainless steels used as fuel cladding in both PWRs and BWRs in the US through the early 1980s [13].

Candidate alternate cladding materials offer several advantages relative to using Zircaloy in an LWR, including significantly slower oxidation kinetics in HT steam $[3,11,14,15]$ and superior HT strength for the metallic candidates; however, their use in LWRs also introduces several challenges. For example, $\mathrm{FeCrAl}$ absorbs more neutrons than Zircaloy and thus negatively affects the neutron economy of the system. Maintaining cycle length therefore requires design changes, including using a thinner $\mathrm{FeCrAl}$ cladding as supported by its increased strength and the reduced thicknesses used by historic iron-based cladding [13], or using increased uranium enrichment. Figure 1 shows continuous-energy macroscopic neutron absorption cross sections for several clad material options of interest which are calculated using JANIS 3.4 with ENDF/B-VII.1 data and without any flux weighting to keep them problem-independent. The thermal macroscopic absorption cross sections for FeCrAl, 304SS, and 310SS are over an order of magnitude higher than those for SiC and Zircaloy. Although the absorption cross section for SiC looks promising, low thermal conductivity in SiC leads to elevated fuel temperatures $[7,16]$, as well as a large temperature gradient across the cladding that in turn induces large thermal stresses across the cladding thickness [17]. 


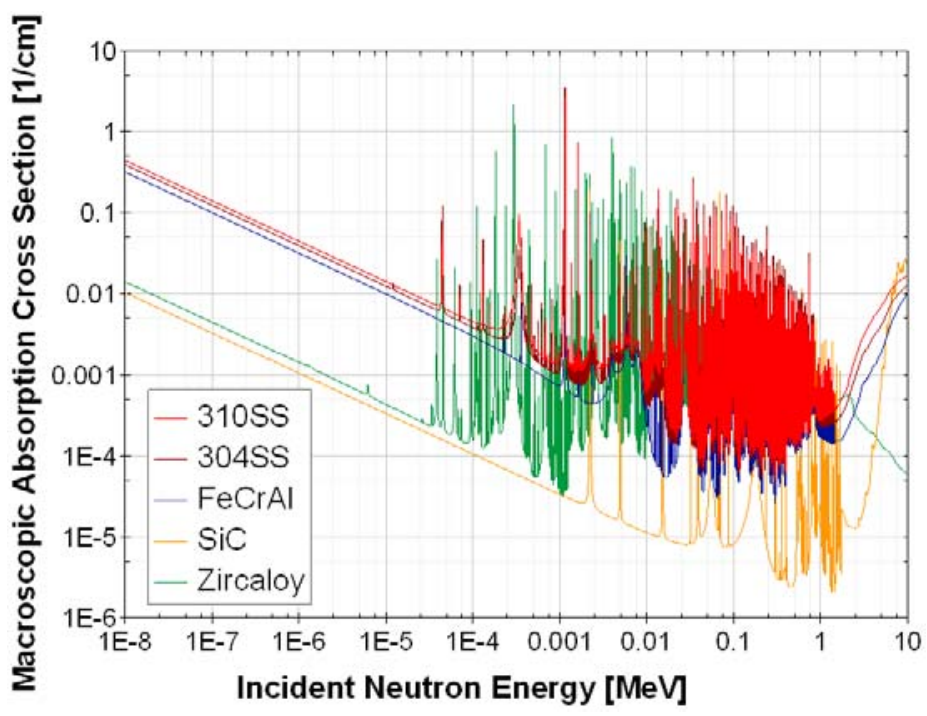

Fig. 1. Macroscopic neutron absorption cross sections for several clad material options.

Table 1 summarizes several important parameters for Zircaloy, $\mathrm{FeCrAl}$, and $\mathrm{SiC}$, including elemental composition, density, and macroscopic thermal neutron absorption cross section $\left(\Sigma_{\text {abs }}^{\text {therm }}\right)$ taken at a neutron energy of $0.253 \mathrm{eV}$. This table does not include 304SS or 310SS because the analysis results indicated that $\mathrm{FeCrAl}$ offered substantially better neutronic performance than $310 \mathrm{SS}$.

Table 1. Summary of relevant data for key cladding material options

\begin{tabular}{lccc}
\hline Clad material & Density $\left(\mathbf{g} / \mathbf{c m}^{\mathbf{3}}\right)$ & Composition $(\mathbf{w t} \%)$ & $\boldsymbol{\Sigma}_{\mathbf{a b s}}^{\text {therm }}\left(\mathbf{c m}^{-\mathbf{1}}\right)$ \\
\hline Zircaloy & 6.56 & $98.26 \mathrm{Zr}, 1.49 \mathrm{Sn}, 0.15 \mathrm{Fe}, 0.1 \mathrm{Cr}$ & 0.0028 \\
$\mathrm{FeCrAl}$ & 7.1 & $75 \mathrm{Fe}, 20 \mathrm{Cr}, 5 \mathrm{Al}$ & 0.0634 \\
$\mathrm{SiC}$ & 2.58 & $70.08 \mathrm{Si}, 29.92 \mathrm{C}$ & 0.0021 \\
\hline
\end{tabular}

\subsection{SUMMARY ASSESSMENT OF ATF CLADDING MATERIALS IN PWRS}

Alternate cladding material options for application in PWRs have been assessed using two-dimensional (2D) pin cell models in SCALE/TRITON from SCALE 6.1.2 with ENDF/B-VII.0 cross-section data [1820]. The reference case geometry was based on a Westinghouse $17 \times 17$ PWR fuel rod. Modeling the fuel as a single repeating pin cell with reflective boundary conditions enabled a large number of cases to be run in a short period of time. Calculations performed for a $2 \mathrm{D}$ quarter-lattice of a Westinghouse $17 \times 17$ assembly verified that the pin cell results were reasonable. A nonlinear reactivity model was used to approximate a multibatch loading scheme in a typical modern Westinghouse $17 \times 17$ PWR using three fuel batches and 18-month cycles. This model accounts for integral reactivity over the fuel's lifetime in order to increase fidelity for nonlinearity in steel cladding results. The study required that the end of cycle (EOC) reactivity of ATF concepts matched that of the reference $\mathrm{UO}_{2} /$ Zircaloy calculations in order to maintain the operational cycle length of the reactor. Throughout this study, the pitch-to-diameter ratio $(\mathrm{P} / \mathrm{D})$, clad outer diameter, and pellet-cladding gap were kept constant at 1.326, $9.4996 \mathrm{~mm}$, and 82.55 $\mu \mathrm{m}$, respectively. The cladding thickness and $\mathrm{UO}_{2}$ fuel pellet radius were adjusted for cases in which 
cycle length requirements were not met; the fuel pellet radius was adjusted to maintain a constant gap thickness as the inner diameter of the clad changed to achieve the desired cladding thickness. For the Zircaloy base case and $\mathrm{FeCrAl}$, the fuel temperature was kept at an average of $900 \mathrm{~K}$, while the cladding and gap were modeled at $600 \mathrm{~K}$ [21]. For SiC models, the fuel temperature was raised to $1100 \mathrm{~K}$, and the temperature of the clad and gap were raised to $700 \mathrm{~K}$ to account for the reduced thermal conductivity of the clad [17]. The borated water in the system was modeled at $580 \mathrm{~K}\left(0.7119 \mathrm{~g} / \mathrm{cm}^{3}\right)$, with $630 \mathrm{ppm}$ boron for all cases; this concentration represents the average value over an entire fuel cycle for a typical PWR. Cladding material compositions from Table 3.6 were used to model each option. $\mathrm{UO}_{2}$ fuel pellets were modeled with a density of $10.47 \mathrm{~g} / \mathrm{cm}^{3}$ ( $\sim 96 \%$ of theoretical density) and $4.9 \%$ enriched uranium; current batch-average enrichment levels in fresh US PWR assemblies are slightly lower than this value,, but trends continue to show increasing enrichment levels.

A series of depletion calculations were performed to determine combinations of cladding thickness and enrichment that would enable each clad material option to achieve the same cycle length as Zircaloy. Cladding thicknesses and uranium enrichments were varied to map out the design space. If the cladding thickness was varied, then the fuel pellet diameter was varied directly with the clad inner diameter change to maintain a constant pellet-clad gap thickness. Three specific cases of interest were considered for each candidate alternate clad material with regard to matching the Zircaloy cycle length:

I. What cladding thickness would be required if the reference $4.9 \%$ enrichment were maintained?

II. What enrichment would be required if the reference cladding thickness $(571.5 \mu \mathrm{m})$ were maintained?

III. What enrichment would be required if the clad thickness were set to a reasonably conservative value (350 $\mu \mathrm{m}$ for iron-based alloys, $\sim 900 \mu \mathrm{m}$ for $\mathrm{SiC})$ ?

The resulting cladding thickness and enrichment combinations for each case are summarized in Table 2 and illustrated in Fig. 2. Combinations of enrichment and clad thickness to the left and upward of the linear trend line shown for each material in Fig. 2 are expected to meet or exceed PWR cycle length requirements. Reduced neutron absorption in SiC cladding enabled an enrichment of less than $4.9 \%$ to match the Zircaloy cycle length with the reference clad thickness (Case II). The amount of clad thinning assumed in Case I was calculated purely on a neutronics basis to meet the required cycle length; it does not explicitly account for any fuel performance constraints. Table 3 summarizes the data slightly differently for the reference Zircaloy case, Case III for FeCrAl, and Case II for SiC. In addition to reporting the enrichment and cladding thickness combinations that matched the standard $\mathrm{UO}_{2} /$ Zircaloy cycle length, it also provides the specific power used in each case and the resulting discharge burnup at end of life (EOL) after 1500 effective full power days (EFPD). The data in this table illustrate that the increased $\mathrm{HM}$ loading in the $\mathrm{FeCrAl}$ case due to thinning the clad led to a lower specific power demand on the fuel, which correspondingly resulted in lower discharge burnup when operating for the same fuel endurance lifetime (1500 EFPD).

Table 2. Fuel parameter combinations that match cycle length of PWR with Zircaloy cladding

\begin{tabular}{lcccccc}
\hline & \multicolumn{2}{c}{ Case I } & \multicolumn{2}{c}{ Case II } & \multicolumn{2}{c}{ Case III } \\
\cline { 2 - 7 } Material & $\begin{array}{c}\text { Clad } \\
\text { thickness } \\
(\boldsymbol{\mu m})\end{array}$ & $\begin{array}{c}\text { Uranium } \\
\text { enrichment } \\
(\boldsymbol{\%})\end{array}$ & $\begin{array}{c}\text { Clad } \\
\text { thickness } \\
(\boldsymbol{\mu \mathbf { m } )}\end{array}$ & $\begin{array}{c}\text { Uranium } \\
\text { enrichment } \\
(\boldsymbol{\%})\end{array}$ & $\begin{array}{c}\text { Clad } \\
\text { thickness } \\
(\boldsymbol{\mu m})\end{array}$ & $\begin{array}{c}\text { Uranium } \\
\text { enrichment } \\
(\boldsymbol{\%})\end{array}$ \\
\hline Zircaloy & 571.5 & 4.9 & 571.5 & 4.9 & 571.5 & 4.9 \\
$310 \mathrm{SS}$ & 226.3 & 4.9 & 571.5 & 6.38 & 350 & 5.39 \\
FeCrAl & 302.2 & 4.9 & 571.5 & 5.86 & 350 & 5.06 \\
$\mathrm{SiC}$ & 606.7 & 4.9 & 571.5 & 4.81 & 889 & 5.5 \\
\hline
\end{tabular}




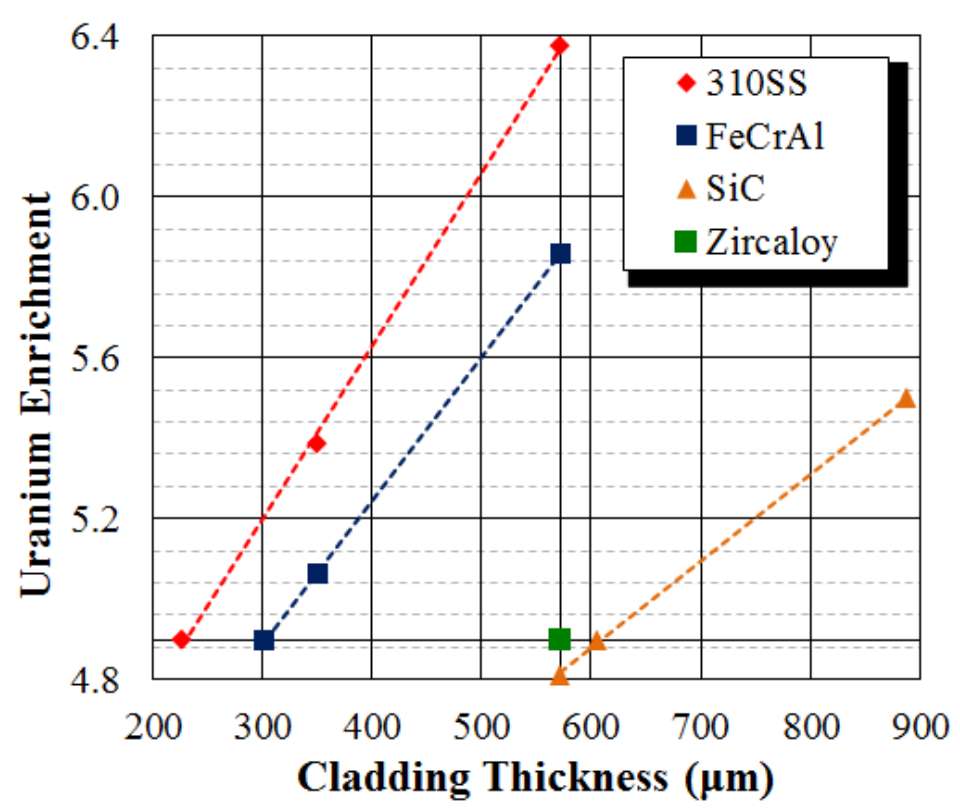

Fig. 2. Fuel parameter combinations that match cycle length of PWR with Zircaloy cladding.

Table 3. Fuel specifications for ORNL PWR ATF analyses

\begin{tabular}{lccc}
\hline Parameter & $\begin{array}{c}\mathbf{U O}_{2} \\
\text { / Zircaloy }\end{array}$ & $\begin{array}{c}\mathbf{U O}_{2} \\
\text { / FeCrAl }\end{array}$ & $\begin{array}{c}\mathbf{U O}_{2} \\
/ \mathbf{S i C}\end{array}$ \\
\hline${ }^{235}$ U enrichment & $4.9 \%$ & $5.06 \%$ & $4.9 \%$ \\
Cladding thickness $(\mu \mathrm{m})$ & 571.5 & 350 & 571.5 \\
Specific power $(\mathrm{MW} / \mathrm{tHM})$ & 38.33 & 34.49 & 38.33 \\
Fuel endurance (EFPD) & 1500 & 1500 & 1500 \\
Discharge burnup (GWd/tHM) & 57.5 & 51.7 & 57.9 \\
\hline
\end{tabular}

This neutronics assessment of PWR alternate cladding material options indicates that iron-based alloys require increased uranium enrichments and/or decreased cladding thicknesses to match the PWR operational cycle length attained with Zircaloy cladding. FeCrAl offered the smallest reactivity penalties, whereas austenitic steel (310SS) showed large negative reactivity impacts. SiC performed well using the standard Zircaloy thickness, but large increases in clad thickness would have negative impacts on reactivity and fuel temperatures. As noted above, the reference value of $4.9 \%$ for uranium enrichment exceeds current industry practice for commercial PWRs in the US; if this value were brought closer to existing batch-average uranium enrichments of around $4.5 \%, \mathrm{UO}_{2} / \mathrm{FeCrAl}$ could match $\mathrm{UO}_{2} /$ Zircaloy cycle length without exceeding 5\% enrichment. Finally, it should be noted that all of the ATF concepts discussed in this section require a great deal of further analysis, including full-core analysis to evaluate design margins under both standard operation and accident scenarios for neutronic, thermal-hydraulic, and fuel performance parameters. 


\section{BWR LATTICE PHYSICS ASSESSMENT OF ATF CLADDING MATERIALS}

While analyzing ATF cladding material options in PWRs was relatively straightforward and could be accomplished through pin cell calculations with some confirmatory quarter-lattice calculations, assessment of candidate ATF cladding materials in BWRs requires a significantly different methodology and more effort due to the inherently more complex structures and designs used in BWR fuel bundles. BWR heterogeneities include axial and radial enrichment and gadolinium loading variations, partiallength (vanishing) fuel rods, and significant axial variation in coolant void distributions.

Initial BWR work focused on using lattice physics calculations to understand the overall behavior of ATF cladding materials in BWRs. Subsequent calculations moved to quarter-core analyses to capture higher order effects and focus on core-level differences such as fuel shuffling approaches, power distributions, and control blade insertion patterns. It was important to model modern bundle designs relevant to today's commercial BWRs. Therefore, BWR $10 \times 10$ enrichment/gadolinium layouts [22-24] were chosen as a basis for producing lattice arrays such as the one shown in Fig. 3, which represents a modern GE12 or GE14 bundle. This lattice contains $92 \mathrm{UO}_{2}$ fuel rods, 9 of which contain gadolinium to hold down initial reactivity and help control power peaking. The two large (purple) circles in the center represent water holes used to increase moderation. The channel box (yellow) surrounding the $10 \times 10$ array isolates coolant (pink) from adjoining bundles and enables a highly moderated interbundle region where control elements will be effective. The fuel pellet and cladding temperatures were modeled as $950 \mathrm{~K}$ and $620 \mathrm{~K}$. The coolant was modeled at $540 \mathrm{~K}$, with a $40 \%$ coolant void fraction used in the initial case. Reflective boundary conditions were used to simulate an infinite array of fuel bundles.

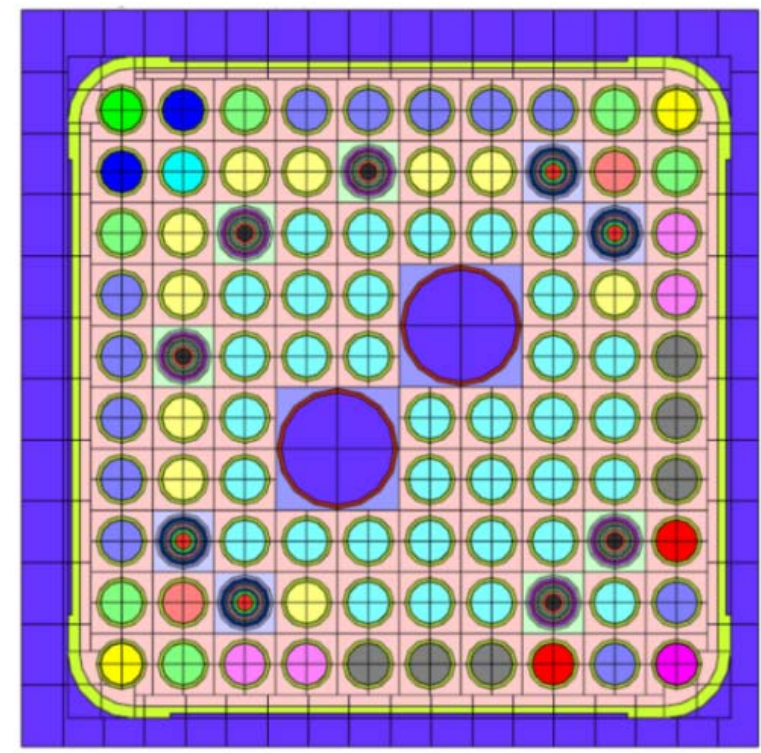

Fig. 3. Illustration of a $10 \times 10 \mathrm{BWR}$ lattice modeled with TRITON.

A reference cladding thickness of $600 \mu \mathrm{m}$ and channel box thickness of $1600 \mu \mathrm{m}$ were used. Initially, Zircaloy was modeled in the cladding and channel box in order to establish a base case. All Zircaloy was then replaced with $\mathrm{FeCrAl}$ to assess the neutronic penalty. When replacing Zircaloy with the higher absorbing FeCrAl, the cladding and channel box thicknesses were reduced in order to decrease parasitic neutron absorption and to increase the HM loading within each fuel pin. The channel boxes contain about half of the total Zircaloy in the core for a reference BWR. Therefore, maximizing the severe accident benefits of any ATF cladding material requires swapping both the channel box and the clad, but this conversely makes any neutronic penalties for that material more severe in BWRs than in PWRs. 
This report focuses on the application of FeCrAl to BWR as a candidate cladding and channel box material. SiC was also assessed as a cladding material, but due to the minimal neutronic differences compared to Zircaloy, the results for $\mathrm{SiC}$ will not be shown in this report.

\subsection{METHODOLOGY}

Initial lattice physics calculations were performed using a quarter-bundle lattice in SCALE/TRITON from SCALE $6.1[18,19]$ in order to determine the reactivity penalty of FeCrAl bundles prior to manipulating the fuel design. A methodology similar to the linear reactivity model [25] was established that integrated reactivity over time in order to allow comparisons of EOC reactivity. This was similar to the approach used in PWR analysis [6]. Representative enrichment and gadolinium layouts for GE $10 \times 10$ bundles were developed on the basis of existing literature [23]. Three different enrichment/gadolinium arrays were used to represent the three major fuel zones found in modern BWR bundles: the power-shaping zone (PSZ) at the bottom, the dominant region (DOM) in the middle, and the vanishing region (VAN) at the top. The PSZ and DOM zones contain 92 fuel pins with enrichments ranging from $2.00 \%$ to $4.90 \%{ }^{235} \mathrm{U}$ and a volume-weighted bundle-average enrichment of 4.11. The VAN region contains 14 vanished rods wherein the fuel pins are replaced by water. Fig. 4 illustrates where each lattice is located axially within the fuel bundle.

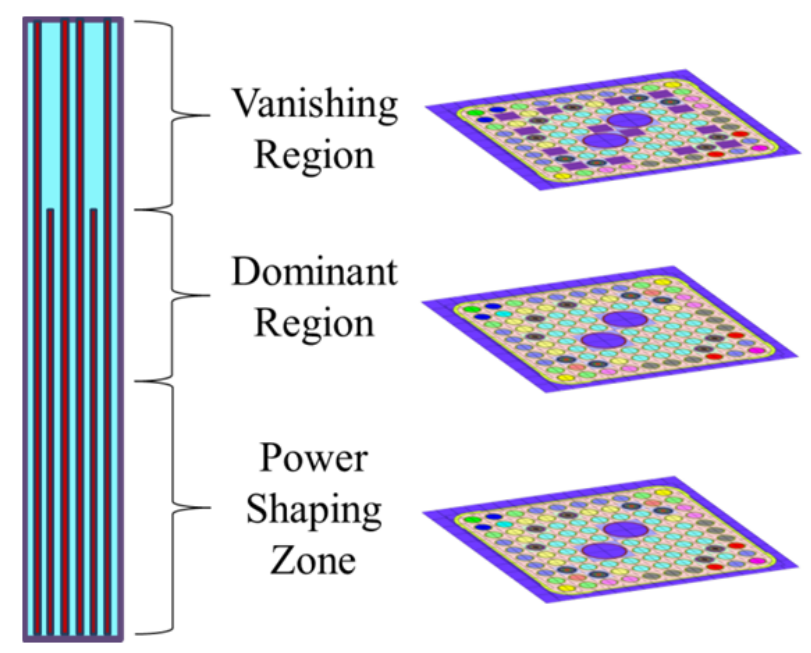

Fig. 4. Allocation of lattices within BWR fuel bundle.

A parametric study was performed to encompass the design space. CASMO-4 [26] was used instead of TRITON to enable assessment of numerous combinations of batch-average enrichment and clad/channel box thickness within a reasonable timeframe while producing depletion results similar to TRITON. A realistic loading pattern was established to determine the cycle length that each design could achieve using exposure data from Peach Bottom Unit 2 Cycle 17 (PB2C17) [27] to represent modern BWR designs. The core used a three-batch scheme and operated with GE14 fuel bundles, making it consistent with the method and models developed. Figure 3 illustrates an exposure map from PB2C17, displaying beginning-of-cycle (BOC) burnup for each bundle in units of GWd/MTU. 


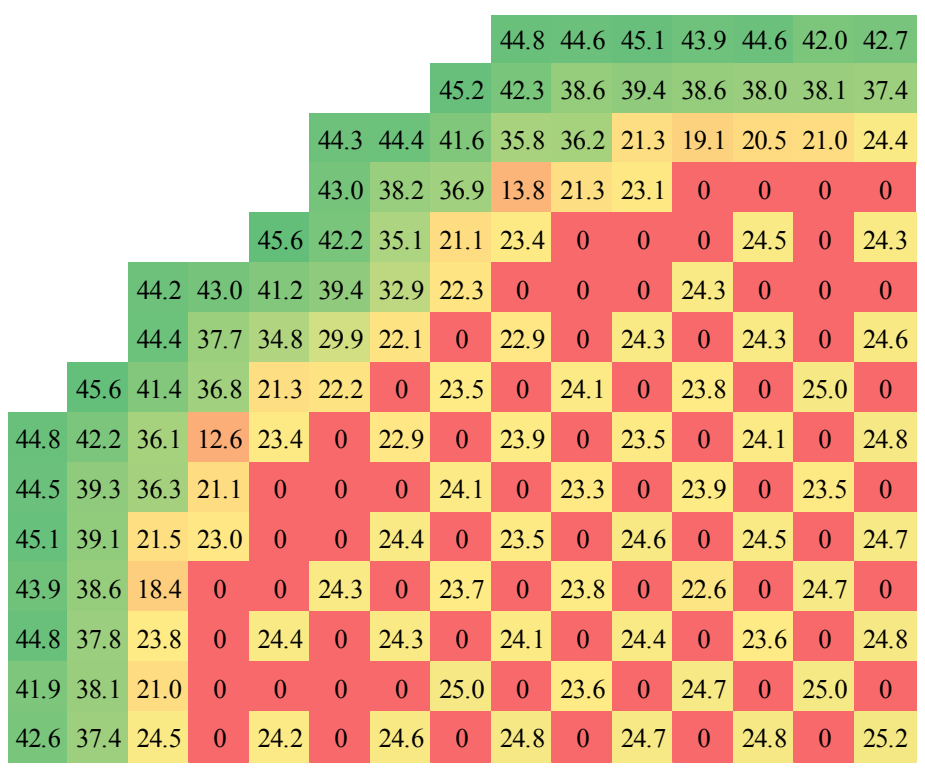

Fig. 5. Representative GE BWR quarter core exposure map for $\mathrm{PB} 2 \mathrm{C} 17$ [27].

Red locations with a zero burnup represent fresh feed assemblies, while depleted cells in yellow represent once-burned assemblies, and those in green represent twice-burned assemblies. Batch-specific core fractional volume, relative assembly power, and discharge burnup were then defined for each batch. For example, Batch 1 consists of 272 fresh assemblies, which is $36 \%$ of the 764 total assemblies present in this BWR core. These batch-specific volume fractions and relative assembly powers were used as input parameters for depletion calculations to account for power sharing in the core. The axial power shape for a generic BWR was also needed; this was calculated for each lattice type (PSZ, DOM and VAN) using relative axial power factors from traversing in-core probe (TIP) data in a Peach Bottom Unit 2 operations report [28], as shown in Fig. 6.

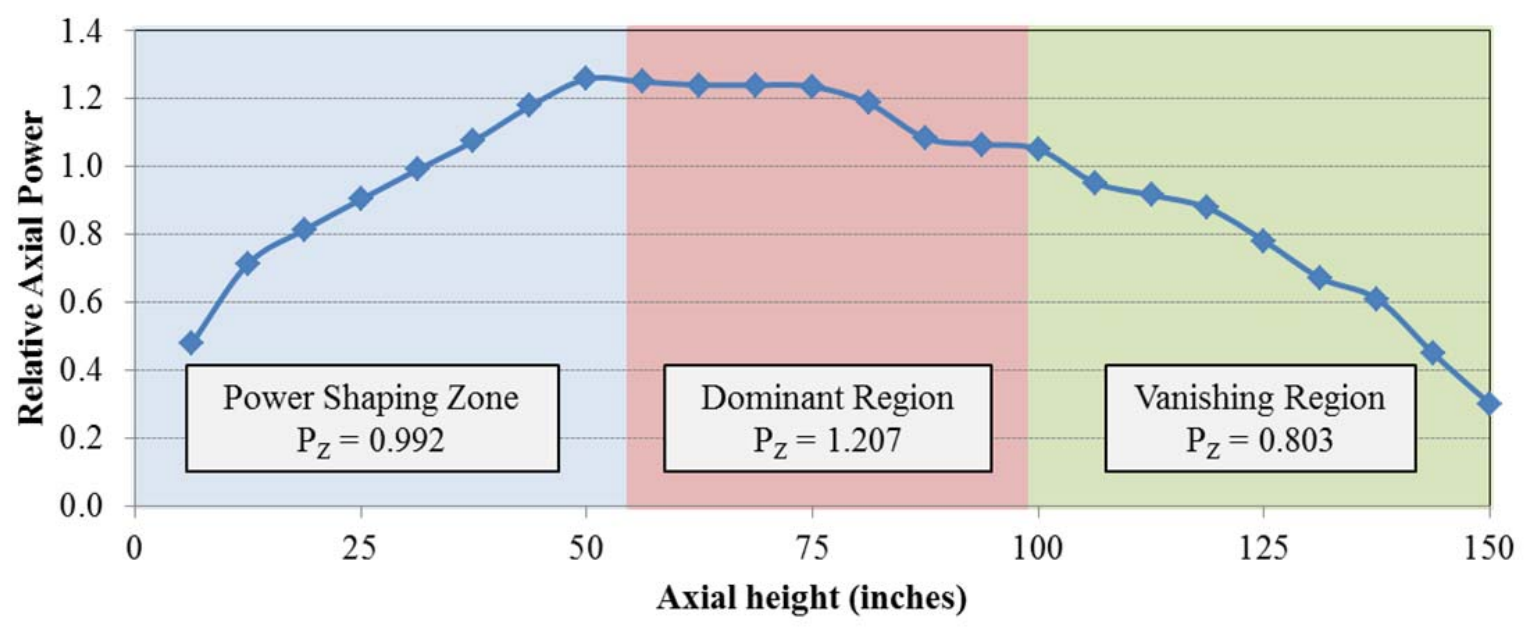

Fig. 6. Relative axial power from PB2C1 TIP data [28].

For this EOC reactivity method, the natural enriched regions at the top and bottom of each assembly were neglected. Also, additional regions of the bundles were considered when creating the full-core models that will be described later in the study. 


\subsection{RESULTS}

Similar to the PWR results shown in Sect. 2.1, initial BWR calculations showed that the neutronic performance of $\mathrm{SiC}$ pwas very similar to Zircaloy while FeCrAl produced a heavy neutronic penalty due to increased neutron absorption. This penalty was in fact larger in BWRs than in PWRs due to swapping the channel box material in addition to the fuel cladding. Figure 7 shows $\Delta \mathrm{k}$-infinity (\%) for three cases to illustrate the relative contributions of cladding and channel box to the combined reactivity penalty: (1) FeCrAl channel box and Zircaloy cladding, (2) FeCrAl cladding and Zircaloy channel box, and (3) FeCrAl cladding and channel box. The change in k-infinity was calculated as

$$
\Delta \mathrm{k} \text {-infinity }=\frac{\left(\mathrm{k}_{1}-\mathrm{k}_{2}\right)}{\mathrm{k}_{1}},
$$

where $\mathrm{k}_{1}$ and $\mathrm{k}_{2}$ represent the $\mathrm{k}$-infinity value for Zircaloy and $\mathrm{FeCrAl}$ designs, respectively.

The depletion of gadolinium, which is a burnable poison used to suppress reactivity in fresh fuel, causes a nonlinear shape to the FeCrAl reactivity penalty, as illustrated in Fig. 7. This minimizes the penalty of $\mathrm{FeCrAl}$ early in life because thermal neutron absorption in gadolinium remains roughly constant regardless of the cladding material used. The FeCrAl cladding absorbs more thermal neutrons as the gadolinium burns out and causes the $\mathrm{FeCrAl}$ penalty to increase up until about $15 \mathrm{GWd} / \mathrm{tHM}$, after which the $\mathrm{FeCrAl}$ reactivity penalty decreases for the remainder of the depletion lifetime due to increased $\mathrm{Pu}$ breeding caused by the harder neutron spectrum. The results also indicate that the channel box and cladding contribute roughly equivalent portions to the combined FeCrAl reactivity penalty. The channel box reactivity penalty exceeds the cladding penalty early in life, but the cladding penalty surpasses the channel box penalty as gadolinium burns out.

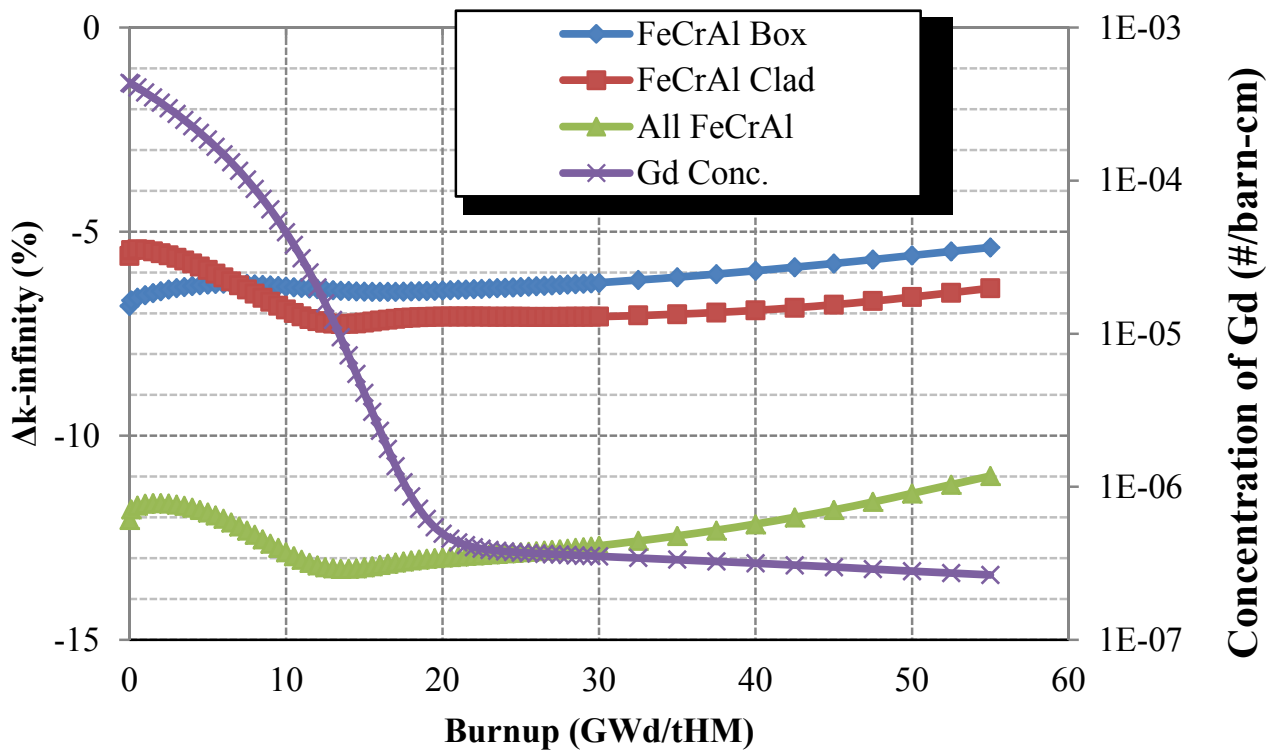

Fig. 7. FeCrAl reactivity penalty of clad and channel box.

Following these initial calculations, a parametric study was performed to identify combinations of design parameters necessary for FeCrAl BWR fuel bundles to maintain the cycle length of standard Zircaloy bundles. These calculations varied two main parameters: (1) the ${ }^{235} U$ enrichment and (2) the relative thickness of the $\mathrm{FeCrAl}$ cladding and channel box. The cladding and channel box were kept at identical relative thicknesses in this study rather than being treated as independently varying parameters. While treating the two thicknesses independently could offer a further degree of freedom in future work, any 
change at all in the channel box thickness would need to be analyzed for its impact on other (nonneutronic) performance aspects. As with PWR analyses, fuel pellet diameters were varied directly with changing cladding thickness in order to maintain a constant pellet-clad gap. This leads to larger fuel pellet diameters and corresponding $\mathrm{UO}_{2}$ mass increases when reducing the cladding thickness, producing a nonlinear reactivity benefit for reduced clad thicknesses. Any reduction in fuel utilization caused by maintaining a constant cycle length with increased uranium loading in the core would be captured in economic analyses rather than enforcing a constant discharge burnup during this neutronic analysis.

Pursuing the same three cases of interest defined in Sect. 2.1, a series of depletion calculations were performed to determine combinations of cladding/channel box thickness and fuel enrichment that would maintain a constant cycle length when using FeCrAl instead of Zircaloy in BWRs. Case I maintained the average enrichment of $4.11 \%$ while thinning the cladding and channel box. Case II maintained constant cladding and channel box thicknesses $(600 \mu \mathrm{m}$ and $1600 \mu \mathrm{m})$ while increasing the ${ }^{235} \mathrm{U}$ enrichment. Case III varied the enrichment and clad/channel box thicknesses simultaneously to identify combinations that matched the Zircaloy cycle length while balancing potential issues with fuel performance (thin clads) or economic costs (enrichments over 5\%). Figure 8 shows the results of calculations performed for Case I (top) and Case II (bottom), with positive values of $\Delta \mathrm{k}$ indicating cases where the EOC reactivity of FeCrAl exceeds that of Zircaloy. Though not stated in the axis label, the channel box was thinned in proportion to the cladding in Case I calculations. For example, if the clad thickness were reduced by $75 \%$ to $150 \mu \mathrm{m}$, then the channel box thickness decreased $75 \%$ to $400 \mu \mathrm{m}$. As expected, reduced cladding and channel box thicknesses or increased ${ }^{235} \mathrm{U}$ enrichments increased the calculated EOC $\Delta \mathrm{k}$.

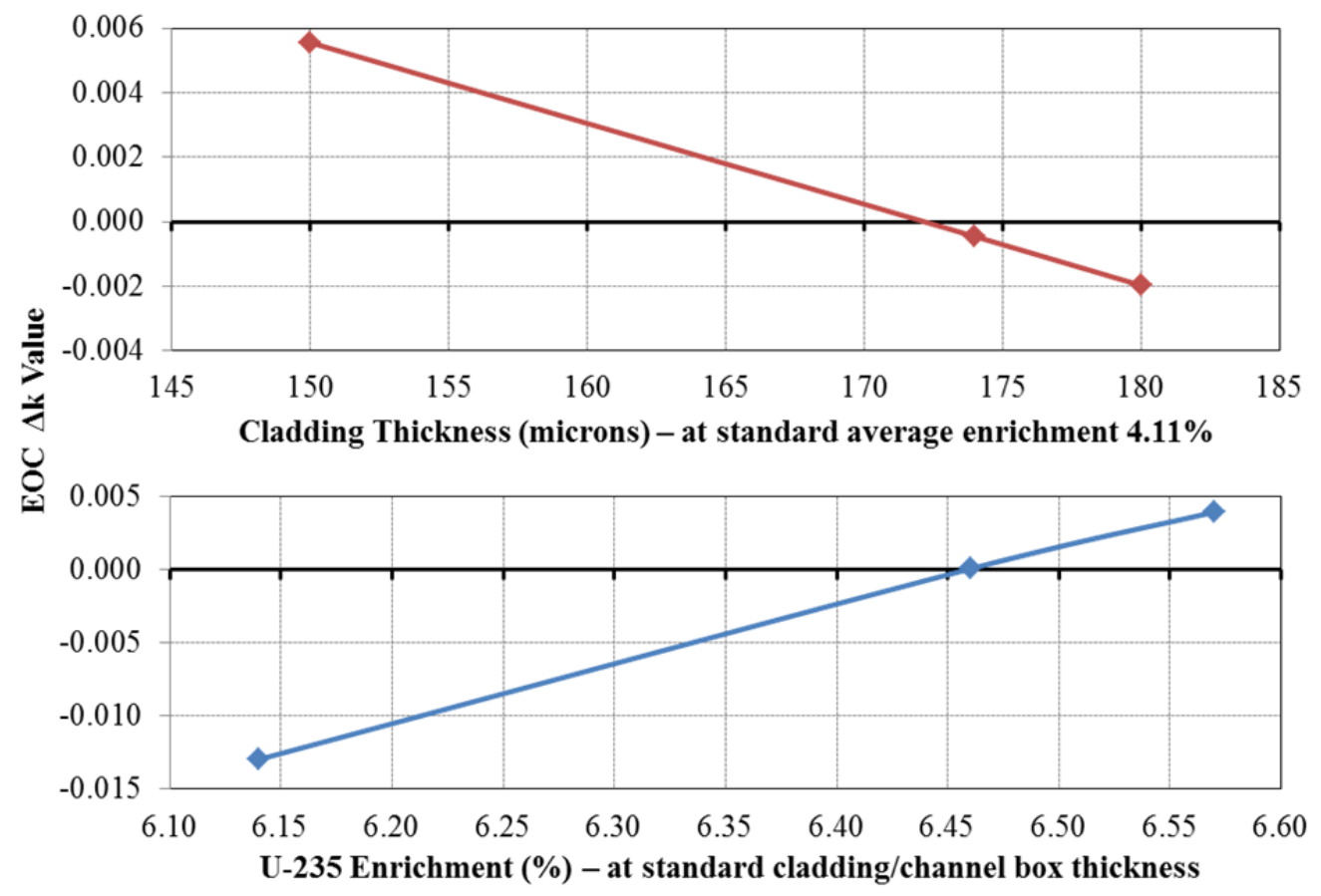

Fig. 8. EOC reactivity values with respect to fuel design changes in FeCrAl loaded bundles.

Results from all three cases, summarized in Table 4 and Fig. 9, indicate that maintaining the reference BWR cycle length while switching from Zircaloy to $\mathrm{FeCrAl}$ requires a $70 \%$ reduction in cladding and channel box thicknesses $(172 \mu \mathrm{m}$ and $460 \mu \mathrm{m})$ when maintaining $4.11 \%$ enrichment (Case I), an average enrichment of $6.46 \%{ }^{235} \mathrm{U}$ at reference cladding and channel box thicknesses (Case II), or a combination of changes such as a 50\% reduction in cladding and channel box thicknesses $(300 \mu \mathrm{m}$ and $800 \mu \mathrm{m})$ with an average enrichment of $4.72 \%$ (Case III). Figure 9 shows two possible solutions for Case III (a and b). 
Table 4. FeCrAl fuel parameter combinations that match BWR cycle length of Zircaloy

\begin{tabular}{lcccccc}
\hline & \multicolumn{2}{c}{ Case I } & \multicolumn{2}{c}{ Case II } & \multicolumn{2}{c}{ Case IIIa } \\
\cline { 2 - 7 } Material & $\begin{array}{c}\text { Clad/box thickness } \\
(\boldsymbol{\mu m})\end{array}$ & $\begin{array}{c}\text { Uranium } \\
\text { enrichment } \\
(\mathbf{\%})\end{array}$ & $\begin{array}{c}\text { Clad } \\
\text { thickness } \\
(\boldsymbol{\mu m})\end{array}$ & $\begin{array}{c}\text { Uranium } \\
\text { enrichment } \\
(\mathbf{\%})\end{array}$ & $\begin{array}{c}\text { Clad } \\
\text { thickness } \\
(\boldsymbol{\mu m})\end{array}$ & $\begin{array}{c}\text { Uranium } \\
\text { enrichment } \\
(\%)\end{array}$ \\
\hline Zircaloy & $600 / 1600$ & 4.11 & $600 / 1600$ & 4.11 & $600 / 1600$ & 4.11 \\
FeCrAl & $172 / 460$ & 4.11 & $600 / 1600$ & 6.46 & $300 / 800$ & 4.72 \\
\hline
\end{tabular}

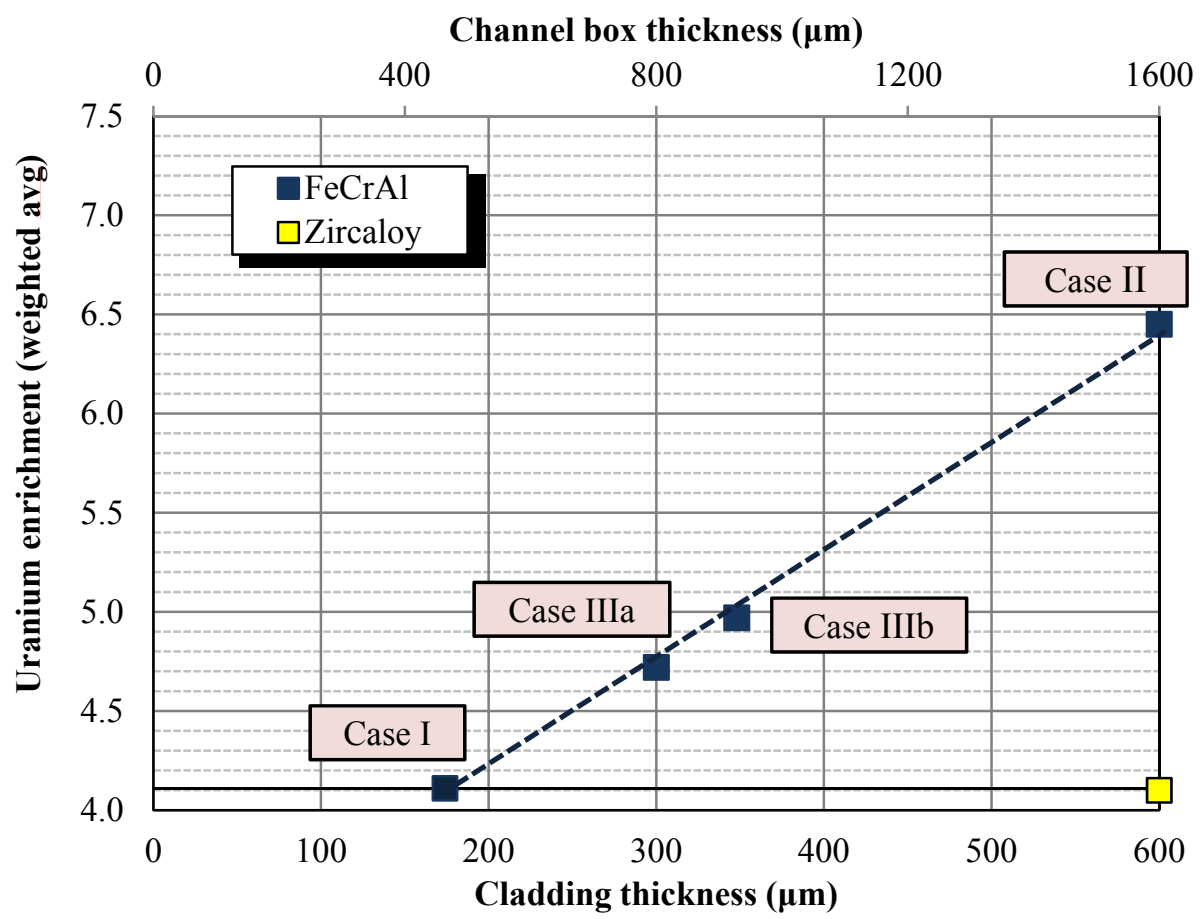

Fig. 9. Fuel parameters required for $\mathrm{FeCrAl}$ to match the Zircaloy core lifetime.

The results in Fig. 9 appear to be roughly linear for FeCrAl. Case IIIa was chosen using $300 \mu \mathrm{m}$ as an estimated lower bound for cladding thickness given that historic austenitic steel LWR cladding was manufactured and operated with at a similar thickness [13]. Case IIIb was chosen using 5.0\% as an upper bound for ${ }^{235} \mathrm{U}$ enrichment to avoid violating the current 5.0\% enrichment limit in place for many fuel cycle facilities and processes in the US.

\subsection{DISCUSSION}

While these lattice physics neutronics results should not be extrapolated beyond what they can accurately predict, they indicate that the reactivity penalty of $\mathrm{FeCrAl}$ is slightly greater in BWRs than it is in PWRs because of the additional metal mass introduced by channel boxes. The use of gadolinium as a burnable absorber produces a nonlinear reactivity penalty during depletion. This is shown here for BWRs, but it could also apply to PWRs. For example, some fuel assemblies in combustion engineering PWRs use gadolinium to hold down reactivity near the large water holes in the assemblies.

The Case III results shown in Table 4 and Fig. 9 indicate a possible design space for replacing Zircaloy with $\mathrm{FeCrAl}$ in BWRs when combining increased enrichments with decreased clad and channel box thicknesses. It should be noted that although Case III results are below the $5 \%$ enrichment limit, these are 
batch-average enrichments of all of the pins in a lattice. If current relative enrichment zoning patterns were maintained, using a batch-average enrichment of 4.72\% (Case IIIa) in the DOM region lattice would require pin-specific enrichments ranging from $2.3 \%$ at the corners to $5.64 \%$ near the water holes. The challenges identified in finding FeCrAl thicknesses that perform well thermomechanically (not too thin) and neutronically (not too thick) while also keeping peak pin enrichments below the current $5 \%$ limit point towards will be further explored in core-level analyses.

Though not shown here, BWR lattice analyses found the neutronic performance of SiC cladding and channel boxes to be very similar to Zircaloy when using reference thicknesses. This trend agrees well with the PWR results shown in Fig. 2 and makes sense conceptually because both Zircaloy and SiC are relatively transparent to neutrons. 


\section{BWR CORE-LEVEL ASSESSMENT OF ATF CLADDING MATERIALS}

While lattice physics calculations provide useful insight regarding the behavior and possible penalties of candidate ATF cladding materials in BWR systems, proper assessment of the neutronics impacts of ATF concepts requires full-core neutronics calculations to examine issues such as power sharing between fuel bundles, core loading pattern strategies, control blade insertion patterns, and safety-related items, including power peaking and reactivity coefficients. This work analyzes these issues as they relate to neutronics performance during plant conditions within normal operation (NO) and anticipated operational occurrences (AOOs). Additional analyses are needed to assess thermal-hydraulic and thermomechanical fuel performance aspects of $\mathrm{NO}$ and $\mathrm{AOO}$ conditions, as well as multidisciplinary analysis of design basis accidents (DBAs) and BDBAs.

\subsection{METHODOLOGY}

Core-level calculations for BWRs were performed using a two-step process typical for the nuclear energy industry. Detailed lattice physics calculations were performed for each fuel bundle and lattice type using a method of characteristics code to generate cross sections and other required parameters. This was followed by core-level calculations that were performed using a nodal simulator code with input from the method of characteristics lattice calculations. Section 4.1.1 provides further information about the lattice physics step, while Sect. 4.1.2 describes the nodal simulator calculations in more detail. Section 4.1.3 then describes the specifics of how this approach was applied to assess FeCrAl as a candidate ATF cladding material in BWRs.

For the full-core model, the natural enriched (NAT) regions (axial blankets) located at the top and bottom of a standard BWR fuel assembly were included. However, for the parametric study, $\mathrm{UO}_{2}$ enrichment was only perturbed in the three middle zones (PSZ, DOM and VAN). The lower NAT zone contains $92 \mathrm{UO}_{2}$ fuel pins, while the top NAT zone contains only 78 due to vanishing rods.

\subsubsection{Lattice Physics Cross Section Generation Models}

Full-core BWR simulations were performed using the latest version of the NESTLE nodal diffusion simulator [29-31]. In order to run NESTLE, few-group cross sections needed to be obtained from a lattice physics code. The lattice physics calculations in this study were performed with CASMO-4, which uses the method of characteristics approach to solve the $2 \mathrm{D}$ neutron transport equation in 70 energy groups with ENDF/B-VI cross section libraries. In the lattice model, the control blade is located in the northwest corner when present. The cruciform blade thickness is $0.792 \mathrm{~cm}$ and consists of homogenized water and steel surrounding $0.50 \mathrm{~cm} \mathrm{~B}_{4} \mathrm{C}$ cylinders.

Each CASMO lattice calculation also included branch perturbations of fuel properties to provide cross section data needed in NESTLE to encompass the expected thermal-hydraulic parameter ranges.

Therefore, each of the five axial zones was run in CASMO at the base case conditions, with a high and low fuel temperature and coolant quality, with and without control blade insertion. The base case and all branch perturbations were run with the control blade fully withdrawn and fully inserted. The nominal case and 9 branch cases were all depleted to a burnup of $65 \mathrm{GWd} / \mathrm{MTU}$.

\subsubsection{Core-level Neutronics Models}

The NESTLE nodal simulator was selected to model the full core BWR neutronics because of its proven ability to effectively model LWRs [30]. Using the nodal expansion method, NESTLE solves the neutron diffusion equation with thermal hydraulic feedback under steady-state and transient core conditions. Due 
to the unavailability of public BWR core models containing advanced $10 \times 10$ fuel bundles, many assumptions and approximations and results from prior work [32] were used to assist in the development of a representative BWR core model for this analysis.

Due to the quarter-core symmetry present in commercial reactors, a quarter-core model with cyclic inner boundary conditions was used. Zero flux boundary conditions were used at the outer periphery of the reflector region. Homogenized cross section data for subcooled water were placed 9 inches above and below the active fuel region and extending 12 inches from the periphery of the core, radially. Similar to the upper NAT region, cross section data used for the upper reflector were calculated with an $80 \%$ void. It was determined that equilibrium core conditions offered the best way to compare alternate cladding material to Zircaloy. Therefore, the core model consisted of three fuel batches: fresh feed, once-burned, and twice-burned assemblies. A representative BOC exposure map and axial power profile were established [23] as shown in Fig. 10.

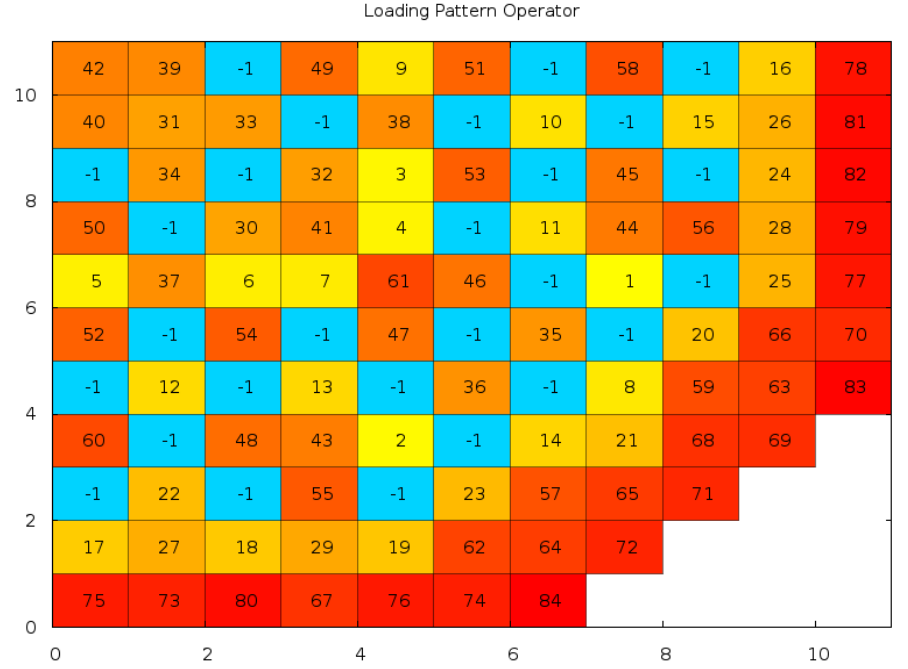

(a)

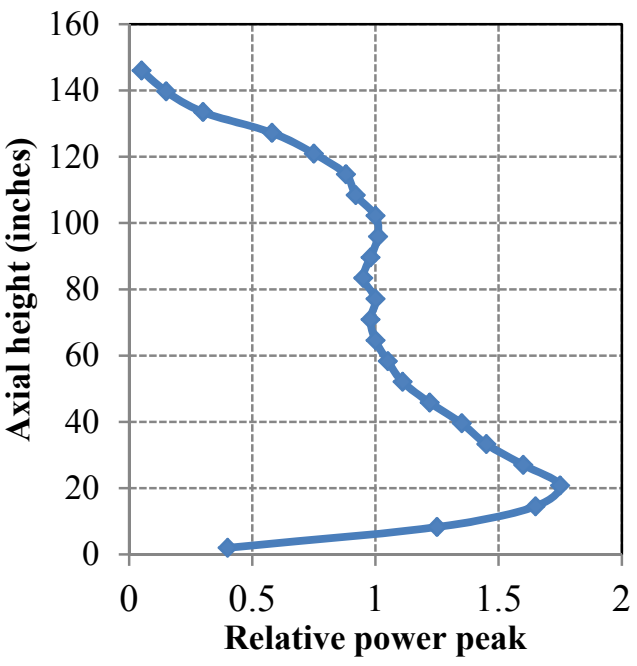

(b)

Fig. 10.a. BOC bundle exposures in BWR core; and b. Hot axial power profile of DOM region.

In Fig. 10(a), the blue bundles denoted with -1 represent fresh feed assemblies, while the yellow/orange and red cells represent once- and twice-burned assemblies, respectively. Burned assemblies are ranked from lowest to highest according to exposure. Consistent with most commercial US core designs, twiceburned assemblies with the highest burnups are placed on the core periphery. Values correspond to BWR fuel with a Zircaloy cladding thickness of $600 \mu \mathrm{m}$ and a fuel pellet radius of $0.440 \mathrm{~cm}$. When replacing Zircaloy with $\mathrm{FeCrAl}$ in the parametric study, the $\mathrm{FeCrAl}$ cladding was thinned to $300 \mu \mathrm{m}$ while the fuel pellet radius was increased to $0.470 \mathrm{~cm}$. This reduced parasitic neutron capture in the cladding and increased the HM loading in the core. Therefore, a correction factor/multiplier was added to the above exposure map when modeling $\mathrm{FeCrAl}$; values in the exposure (burnup) file were multiplied by $0.440^{2} / 0.470^{2}$ to account for this increase in MTU.

Using a core-average power density of $55.66 \mathrm{~kW} / \mathrm{L}$, the full representative core produces $1910 \mathrm{MWt}$. As shown in Fig. 10(a), the quarter-core contains 111 fuel bundles. This study used two different bundle types in the BWR core: assembly type 1 contained all five axial zones, while type 2 did not have a PSZ and thus only contained 4 axial zones. The PSZ region contains more gadolinium rods than the DOM region and therefore preferentially suppresses reactivity in the bottom of the core. Core designers strategically mix these two fuel bundle types to minimize power peaking, as was done in this study. Fig. 11 shows four examples of the numerous possible core loading patterns depleted in NESTLE. Locations labeled as 1 and 2 represent assembly type 1 and type 2, while cells labeled as 3 represent reflector 
assemblies consisting of water that surround the periphery of the active fuel region. Initial calculations shuffling the two different assembly designs using Zircaloy cladding/channel boxes identified Case 3 as the best core loading pattern for minimizing relative power peaking factors and extending cycle length. Subsequent calculations used this layout when comparing FeCrAl with Zircaloy.
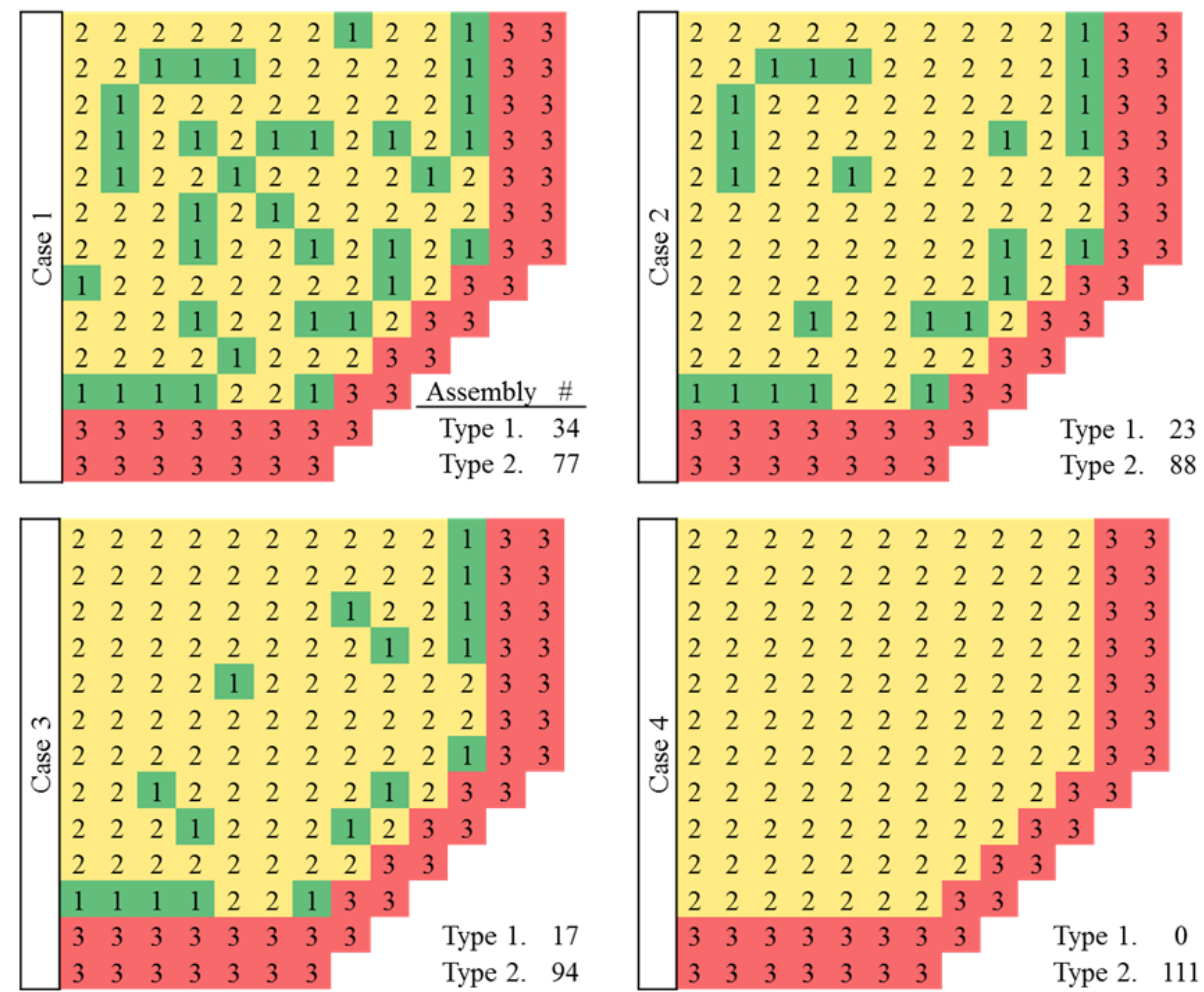

Fig. 11. Assembly configuration optimization.

\subsubsection{Alternate Cladding Full-Core Parametric Study}

Once a full-core BWR base case model was established, a parametric study was performed for FeCrAl. Initially, depletion was performed with the same fuel design by replacing Zircaloy with FeCrAl without changes to enrichment, cladding thickness, or channel box thickness. Preliminary BOC calculations showed subcritical reactivity, which agreed with previous 2D lattice physics results. Therefore, the cladding and channel box thicknesses were reduced while enrichment and pellet diameter of the $\mathrm{UO}_{2}$ fuel were increased in order to increase reactivity and match the cycle length of the full-core Zircaloy base case.

For each modification to the fuel design during the parametric study, new 2D lattice physics calculations were run for each of the three major axial zones to produce updated cross section data. With the updated cross section data, the $\mathrm{FeCrAl}$ full-core models were run again by varying enrichment until the $\mathrm{FeCrAl}$ EOC k-effective equaled that of the Zircaloy base case EOC k-effective, thus matching cycle lengths. The goal of this full-core parametric study was to establish the same bundle modifications in the FeCrAl bundles that were required in the lattice-based EOC reactivity method. Although exact matches were not expected, if similar results were recorded, then the EOC reactivity method would be considered a quick and useful scoping tool as opposed to full core calculations. Detailed results can be found in the complementing paper, "Validation of Full-Core Reactivity Equivalence for FeCrAl Enhanced Accident Tolerant Fuel in BWRs" [1].

If alternate cladding materials were to be commercialized, nuclear utilities would likely not be in favor of large-scale changes to the operation of the reactor. Thus, aside from the lattice physics models used to 
generate the lattice cross sections and the exposure data (for thinned cladding), the full-core NESTLE model was not otherwise altered when modeling FeCrAl. This included core power, boundary conditions, inlet coolant temperature, etc. Since all of the cases maintained the same fuel rod outer diameter, thermal hydraulic parameters were assumed to remain constant for both Zircaloy and FeCrAl. FeCrAl calculations also started with the same loading pattern shown in Case 3 of Fig. 11. These factors were kept constant in order to establish a consistent comparison between the cladding types.

\subsection{RESULTS}

Figure 12 shows the variation of k-effective for the Zircaloy base case depletion with control blades fully withdrawn (uncontrolled). The cycle length was estimated as the time value (in EFPD) for which keffective reached 1.0, with no eigenvalue bias assumed in NESTLE for the Zircaloy or FeCrAl cases. The results indicate that the Zircaloy full-core base case maintains criticality for a burnup of $12.8 \mathrm{GWd} / \mathrm{MTU}$ or 527 effective full power days (EFPD). As gadolinium burns out, the reactivity trajectory steepens. Table 5 summarizes the modeling parameter design specifications used for the Zircaloy full-core reference case, as well as the depletion results.

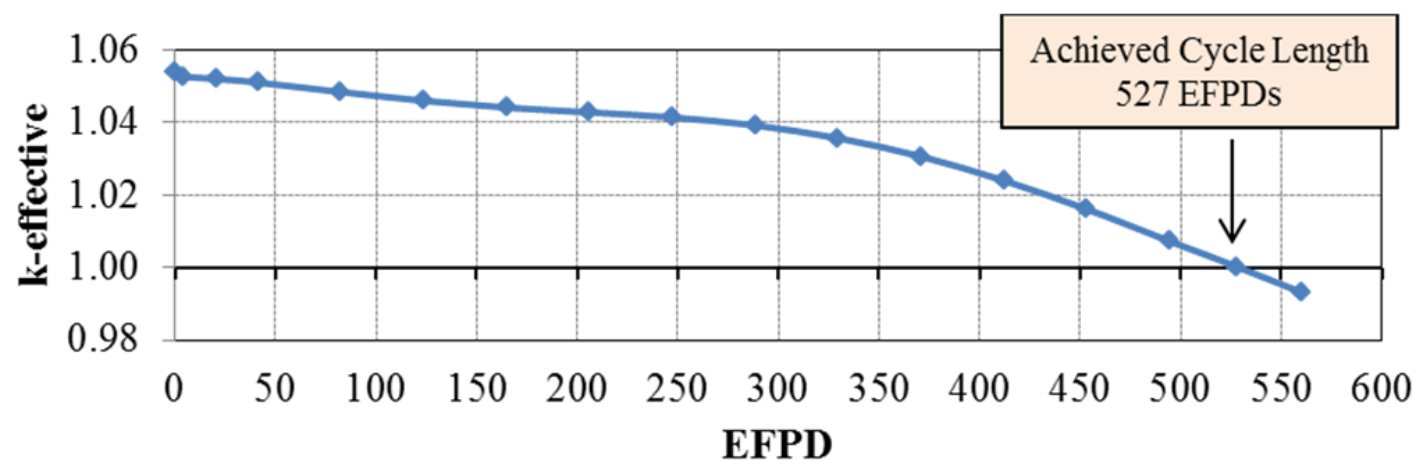

Fig. 12. Full-core Zircaloy base case depletion.

Table 5. Specifications for full-core BWR Zircaloy reference case

\begin{tabular}{lc}
\hline \multicolumn{1}{c}{ Parameter } & Value \\
\hline Quarter core fuel assemblies & 111 \\
Axial fuel nodes & 24 \\
Assembly pin configuration & $10 \times 10$ \\
Core power & $1910 \mathrm{MWt}$ \\
Power density & $55.66 \mathrm{~kW} / \mathrm{L}$ \\
Achieved cycle length & $527.5 \mathrm{EFPD}$ \\
HM loading & $78.72 \mathrm{MTU}$ \\
Burnup accumulation & $12800 \mathrm{MWd} / \mathrm{MTU}$ \\
\hline
\end{tabular}

For the $\mathrm{FeCrAl}$ design to meet reactivity lifetime requirements on a full-core level, its cycle length must reach or exceed that of the Zircaloy base case. Of the four FeCrAl designs in Fig. 9 that met lifetime requirements for lattice-level studies, only two of the designs were carried through to full-core analysis: Case IIIa (300 $\mu \mathrm{m}$ cladding and $800 \mu \mathrm{m}$ channel box with $4.72 \%$ enrichment) and Case II (600 $\mu \mathrm{m}$ cladding and $1600 \mu \mathrm{m}$ channel box with $6.46 \%$ enrichment). Case IIIa was chosen as the lower limit for thinning $\mathrm{FeCrAl}$, and Case II was chosen because its geometry matched the Zircaloy design. For these full-core analyses, Case IIIa is referred to as Case 1, while Case II is referred to as Case 2.

Using the fuel parameter specifications from these cases, a full-core parametric study was performed with FeCrAl calculations to match the Zircaloy base case cycle length of 527 EFPD. Case 2 has the same pellet radius and HM loading as the Zircaloy base case; therefore, Case 2 was depleted for $12.80 \mathrm{GWd} / \mathrm{MTU}$. 
However, Case 1 contained a larger fuel pellet diameter and HM loading (91.72 MTU) and was only depleted to $10.98 \mathrm{GWd} / \mathrm{MTU}$. Starting with the enrichments from the lattice physics results, enrichment was varied until the EOC k-effective values for Cases 1 and 2 were equal to 1.000 (+/- 0.001). Fig. 13 shows the time-dependent full-core k-effective for FeCrAl models that met cycle length requirements, with enrichments of $4.78 \%$ for Case 1 and $6.53 \%$ for Case 2.

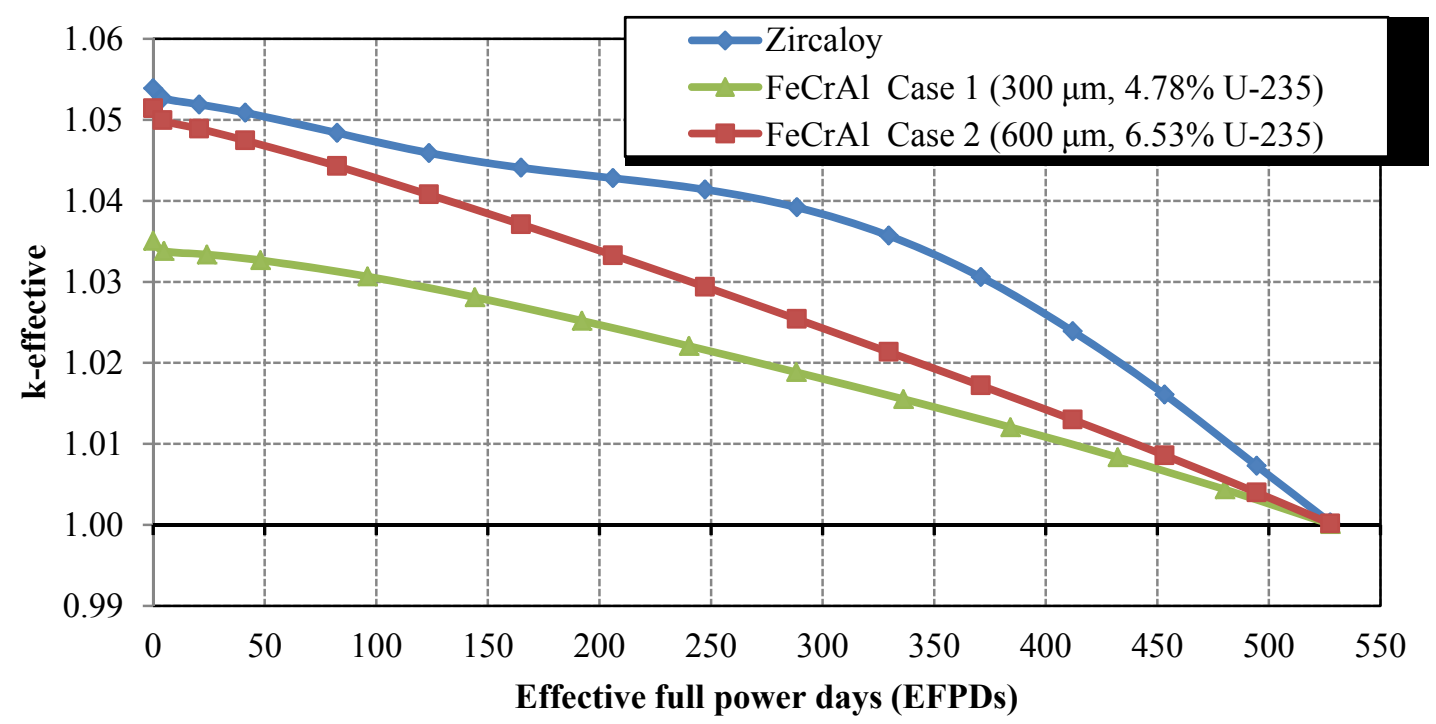

Fig. 13. Full-core FeCrAl designs matching Zircaloy base case cycle length.

The depletion trajectories in Fig. 13 exhibit somewhat divergent behaviors because differences in enrichment and HM loading changes interact with the neutron spectrum and gadolinium loading to produce complicated effects. Case 1 maintains the flattest k-effective curve throughout the depletion cycle because its increased HM loading leads to a flatter burnup distribution across the core. It is expected that Case 1 will produce lower peaking factors than the comparable Zircaloy case when the quarter core is optimized. It is also evident that the Zircaloy base case is affected the most by the presence of gadolinium according to the depletion trajectory showing distinct nonlinear behavior. The increased enrichment in Cases 1 and 2 indicates that the gadolinium in those systems must compete for thermal absorptions with more ${ }^{235} \mathrm{U}$ atoms than in the Zircaloy design, and thus the gadolinium produces a slightly larger effect on reactivity with Zircaloy. Lastly, the reactivity of the Zircaloy design drops much faster near EOC than both $\mathrm{FeCrAl}$ cases because the increased thermal neutron absorption in $\mathrm{FeCrAl}$ produces a harder neutron spectrum in FeCrAl-clad fuel and leads to a higher conversion rate of ${ }^{238} \mathrm{U}$ to ${ }^{239} \mathrm{Pu}$ than in the Zircaloy case. Figure 14 summarizes all of the full-core and lattice physics parameter combinations producing cycle lengths that match the corresponding Zircaloy case, which are overlaid on the same axes. Based upon the results in this figure, lattice physics and full-core results agree quite well. Full-core Case 1 (300 $\mu \mathrm{m}$ thick cladding) required almost identical fuel enrichments to the lattice-level results, while full-core Case $2(600 \mu \mathrm{m}$ thick cladding) required slightly higher enrichment than in lattice calculations. Aside from a slight bias, these results indicate that while full-core 3D nodal simulators provide the best information, it may be reasonable to use $2 \mathrm{D}$ lattice physics calculations to perform rapid parametric studies as a rapid scoping tool prior to core-level analysis. 


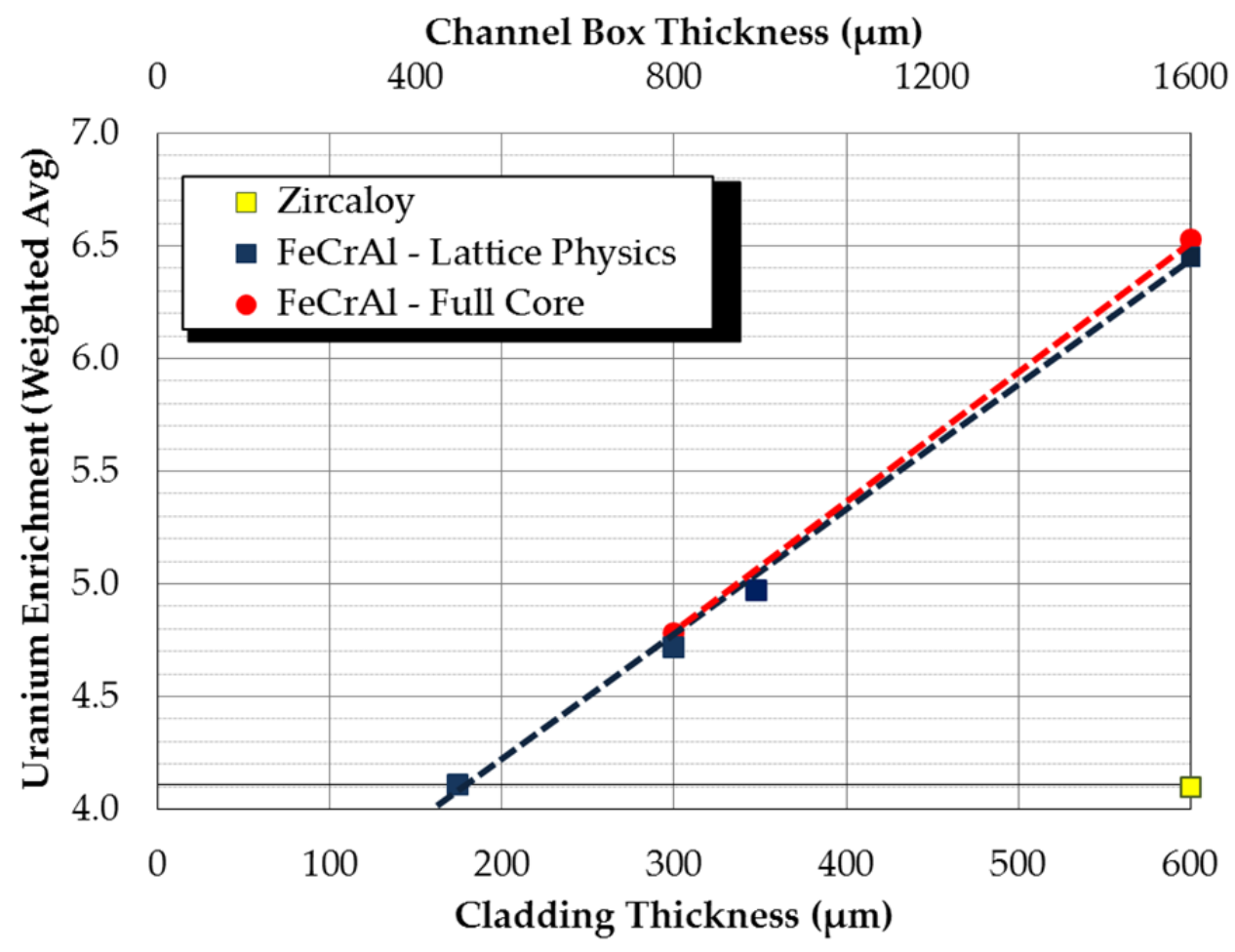

Fig. 14. Parametric evaluation of lattice physics and full-core models.

\subsection{DISCUSSION}

These full-core neutronics analyses identified two possible FeCrAl BWR fuel bundle designs that match the cycle length achieved by Zircaloy. Additional full-core analyses must subsequently investigate issues such as quantifying effects of $\mathrm{FeCrAl}$ on power distributions, loading pattern optimization for a $\mathrm{FeCrAl}$ core, reactivity coefficients, and searching for any other promising concepts or design approaches that could improve the performance of ATF cladding in a BWR.

\subsubsection{Loading Pattern Optimization}

Core loading pattern optimization calculations were performed to analyze numerous different fuel shuffle patterns for $\mathrm{FeCrAl}$ fuel bundles and to account for differences in assembly power sharing and lifetime reactivity trajectory of FeCrAl bundles compared with Zircaloy bundles. New loading patterns were identified that offered better performance than the reference Zircaloy loading pattern and shuffle scheme while still meeting all applicable safety limits (e.g., power peaking) and cycle length requirements. The results from these calculations are not shown here because they are still in progress, but they should be included in upcoming publications.

\subsubsection{Reactivity Coefficients}

Reactivity coefficients for a BWR using FeCrAl fuel bundles were calculated and compared to the Zircaloy reference core. Moderator temperatures, fuel temperatures, and control blade insertion heights were manipulated to investigate their responses in each model.

Core-level analyses confirmed that the FeCrAl BWR core maintained a negative moderator temperature coefficient (MTC) by instantaneous perturbing the inlet coolant temperature of the NESTLE model by $10^{\circ} \mathrm{F}$ at BOC, MOC and EOC. Based on a reference temperature of $527.5^{\circ} \mathrm{F}$, branch calculations were thus simulated at $517.5^{\circ} \mathrm{F}$ and $537.5^{\circ} \mathrm{F}$. Each MTC shown in Table 6 represents the average of both 
perturbations made at each timestep. As indicated by a negative temperature coefficient, reactivity dropped when temperature was increased, and it subsequently increased upon decreasing the coolant temperature.

Table 6. Moderator temperature coefficient $\left(\mathrm{pcm} /{ }^{\circ} \mathrm{F}\right)$

\begin{tabular}{lll}
\hline & Zircaloy & FeCrAl \\
\hline BOC & -47 & -40 \\
MOC & -47 & -46 \\
EOC & -47 & -49 \\
\hline
\end{tabular}

Full-core NESTLE models also assessed the integral reactivity worth of the control blades using simulation branch calculations with all blades fully withdrawn and inserted at BOC, MOC and EOC. The integral reactivity worth of all control blades, shown in Table 7 below, indicate slightly reduced (about $15 \%$ lower) control blade worth when using FeCrAl instead of Zircaloy due to the FeCrAl absorbing more neutrons. Future calculations should assess the impacts of the reduced integral control blade worth.

Table 7. All blades in worth ( $\Delta$ k-infinity)

\begin{tabular}{lll}
\hline & Zircaloy & FeCrAl \\
\hline BOC & -0.246 & -0.210 \\
MOC & -0.248 & -0.207 \\
EOC & -0.235 & -0.205 \\
\hline
\end{tabular}

Finally, the fuel temperature coefficient (FTC) for the FeCrAl BWR fuel bundle was estimated using 2D lattice physics calculations that perturbed the average temperature of the fuel region at each timestep. Rather than use a NESTLE model and assume an isothermal temperature throughout an entire full reactor core, CASMO-4 lattice calculations calculated the FTCs using instantaneous changes in a standalone fuel bundle at beginning of life (BOL), middle of life (MOL) and end of life (EOL). In these calculations, the reference average fuel temperature of $1250.3^{\circ} \mathrm{F}$ was increased and decreased $100^{\circ} \mathrm{F}$. The results in Table 8 demonstrate a slightly negative FTC for both Zircaloy and FeCrAl; FeCrAl appears to have almost no impact on the FTC given the largely negligible differences seen in these results.

Table 8. Preliminary fuel temperature coefficients $\left(\mathbf{p c m} /{ }^{\circ} \mathbf{F}\right)$

\begin{tabular}{lcc}
\hline & Zircaloy & FeCrAl \\
\hline BOL & -1.2 & -1.2 \\
MOL & -1.2 & -1.2 \\
EOL & -0.9 & -0.8 \\
\hline
\end{tabular}

\subsubsection{Other ATF BWR Concepts}

Full-core analyses are also underway to assess the potential benefits of a newly proposed approach for using ATF materials in a BWR by using FeCrAl as the fuel cladding material but replacing the Zircaloy channel box with a chromia-coated $\mathrm{SiC}$ material. Preliminary results from these calculations indicate substantial promise for this concept, with a $300 \mu \mathrm{m}$ thick FeCrAl cladding and this coated-SiC channel box matching the reference Zircaloy cycle length while possibly using an enrichment slightly lower than 
the reference $4.11 \%$ value from the Zircaloy core. Once confirmed, results from this work will be reported in future publications. 


\section{CONCLUSIONS}

Candidate ATF cladding materials offer potential performance improvements during severe accidents if deployed in existing LWRs. While previous analyses from multiple organizations demonstrate that $\mathrm{FeCrAl}$ and $\mathrm{SiC}$ both appear to be neutronically feasible as PWR cladding materials, this current work represents the first neutronic assessment of replacing the Zircaloy cladding and channel box materials in BWRs with FeCrAl. Results from lattice physics and full-core calculations indicate that FeCrAl could achieve acceptable neutronic performance in BWRs in several ways, with the most promising design possibilities involving thinning the $\mathrm{FeCrAl}$ cladding and channel box while slightly increasing batchaverage enrichments in FeCrAl fuel bundles. New loading pattern schemes optimized for a FeCrAl BWR core are being finalized, and the early results indicate potentially promising safety characteristics for using FeCrAl in BWRs based on maintaining negative reactivity coefficients.

Future work in neutronic analysis of LWR ATF concepts should include full-core PWR analysis of both steady-state and transient conditions, further full-core BWR analysis focused on confirming and optimizing an emerging concept using FeCrAl cladding with a chromia-coated $\mathrm{SiC}$ channel box, and integrating neutronic analyses with thermal-hydraulic and thermomechanical fuel performance assessments in order to gain a more complete understanding of the multiphysics behavior of these ATF concepts. All of these analyses are essential to efficient, effective technology development efforts and down-selection between the different candidate technologies to focus larger R\&D efforts on the most promising option(s). 


\section{ACKNOWLEDGEMENTS}

The authors wish to thank Kurt Terrani and Brian Ade for their insights and contributions to this work. Constructive feedback that helped shape this document into a better form was provided by several people including Steve Bowman, Nick Brown, Germina Ilas, Rose Raney, and Will Wieselquist; all of their suggestions and comments are greatly appreciated. This ATF work was funded by the Advanced Fuels Campaign under the US DOE-NE Fuel Cycle Research and Development program. 


\section{REFERENCES}

1. W. J. Carmack, F. Goldner, S. M. Bragg-Sitton, and L. L. Snead, "Overview of the U.S. DOE accident tolerant fuel development program," Proc. 2013 LWR Fuel Performance Meeting/TopFuel 2013, Charlotte, North Carolina, USA, September 15-19, 2013, American Nuclear Society (2013) 734-739.

2. S. J. Zinkle, K. A. Terrani, J. C. Gehin, L. J. Ott, and L. L. Snead, “Accident tolerant fuels for LWRs: A perspective," J Nucl Mater, no. 448 (2014) 374-379.

3. K. A. Terrani, S. J. Zinkle, and L .L. Snead, "Advanced oxidation-resistant iron-based alloys for LWR fuel cladding," J Nucl Mater, no. 448 (2014) 420-435.

4. S. Bragg-Sitton et al., "Light Water Reactor Accident Tolerant Fuel Performance Metrics," FCRDFUEL-2013-000264, Idaho National Laboratory, ID (2014).

5. J. J. Powers, N. M. George, A. Worrall, K. A. Terrani, and G. I. Maldonado, "Reactor physics assessment of alternate cladding materials," Transactions of the 2014 Water Reactor Fuel Performance Meeting/Top Fuel/LWR Fuel Performance Meeting (WRFPM2014/TopFuel 2014), Sendai, Japan (September 14-17, 2014).

6. N. M. George, K. A. Terrani, J. J. Powers, A. Worrall, G. I. Maldonado, "Neutronic analysis of candidate accident-tolerant cladding concepts in pressurized water reactors," Ann Nucl Energy, no. 75 (2015) 703-712.

7. Y. Katoh et al., "Continuous $\mathrm{SiC}$ fiber, CVI SiC matrix composites for nuclear applications: Properties and irradiation effects," J Nucl Mater, no. 448 (2014) 448-476.

8. K. Yueh, D. Carpenter, and H. Feinroth, "Clad in clay," Nucl Eng Int, no. 55 (2010) 14-16.

9. D. M. Carpenter, An assessment of silicon carbide as a cladding material for light water reactors, Doctoral Thesis, Massachusetts Institute of Technology (2010).

10. K. Yueh, K. A. Terrani, "Silicon carbide composite for light water reactor fuel assembly applications," J Nucl Mater, no. 448 (2014) 380-388.

11. B. A. Pint et al., "High temperature oxidation of fuel cladding candidate materials in steam-hydrogen environments," J Nucl Mater, no. 440 (2013) 420-427.

12. KANTHAL, Kanthal APMT (Tube) Material Datasheet, http://kanthal.com/en/products/material-datasheets/tube/kanthal-apmt/ .

13. A. Strasser et al., An Evaluation of Stainless Steel Cladding for Use in Current Design LWRs, Rpt. NP-2642, Electric Power Research Institute (1982).

14. J. V. Cathcart et al., "Zirconium Metal-Water Oxidation Kinetics IV. Reaction Rate Studies," ORNL/NUREG-17, Oak Ridge National Laboratory, TN (1977).

15. K. A. Terrani, B. A. Pint, C. M . Parish, C. M. Silva, L. L. Snead, and Y. Katoh, "Silicon carbide oxidation in steam up to 2 MPa," J. Am. Ceram. Soc., no. 978 (2014) 2331-2352.

16. L. L. Snead et al., "Handbook of SiC properties for fuel performance modeling," J Nucl Mater, no. 371 (2007) 329-377.

17. M. Ben-Belgacem, V. Richet, K. A. Terrani, Y. Katoh, and L. L. Snead, "Thermo-mechanical analysis of LWR SiC/SiC composite cladding," J Nucl Mater, no. 447 (2014) 125-142.

18. M. D. DeHart and S. M. Bowman, "Reactor Physics Methods and Analysis Capabilities in SCALE," Nuclear Technology, no. 1742 (2011) 196-213.

19. SCALE: A Comprehensive Modeling and Simulation Suite for Nuclear Safety Analysis and Design, ORNL/TM-2005/39, Version 6.1, Oak Ridge National Laboratory, TN, USA, (June 2011).

20. M. B. Chadwick et al., "ENDF/B-VII.0: Next generation evaluated nuclear data library for nuclear science and technology," Nucl Data Sheets, no. 107 (2006) 2931-3060.

21. A. T. Godfrey, VERA Core Physics Benchmark Progression Problem Specifications, CASL CASLU-2012-0131-003, Oak Ridge National Laboratory, 2014.

22. H. J. Smith, Analysis of Experimental Data for High Burnup BWR Spent Fuel Isotopic Validation SVEA-96 and GE14 Assembly Designs, ORNL/TM-2013/18, Oak Ridge National Laboratory, 2013.

23. M. L. Fensin, Optimum Boiling Water Reactor Fuel Design Strategies to Enhance Reactor Shutdown by the Standby Liquid Control System, Master's Thesis, University of Florida, 2004. 
24. G. Watford, "Advanced $10 \times 10$ GE BWR fuel design," Proceedings of ANS Topical Meeting on Advances in Fuel Management II (ANFM II), Myrtle Beach, SC, USA, 1997.

25. M. J. Driscoll, T. J. Downar, and E. E. Pilat, The linear reactivity model for nuclear fuel management, American Nuclear Society, La Grange Park, IL, USA, 1990.

26. K. Smith, J. Rhodes, "CASMO-4 characteristics method for two-dimensional PWR and BWR core calculations," Trans. Am. Nucl. Soc, no. 83 (2000) 294.

27. M. Asgari, D. J. Kropaczek, C. C. Oyarzun, J. J. Tusar, and M. M. Heverly, "Application of the NStreaming SM concept to Peach Bottom 2 Cycle 17," Proceedings of the 2006 Topical Meeting on Reactor Physics: Advances in Nuclear Analysis and Simulation (PHYSOR 2006), Vancouver, BC, Canada, 2006.

28. N. Larsen, Core Design and Operating Data for Cycles 1 and 2 of Peach Bottom 2, General Electric Co., San Jose, CA, USA, 1978.

29. P. J. Turinsky et al., Few-Group Neutron Diffusion Equation Solver Utilizing the Nodal Expansion Method for Eigenvalue, Adjoint, Fixed-Source Steady-State and Transient Problems, Electric Power Research Center, North Carolina State University, Raleigh, NC, USA, 1994.

30. N. P. Luciano et al., "The NESTLE 3D Nodal Core Simulator: Modern Reactor Models," Proceedings of the 2015 ANS Joint International Conference on Mathematics and Computation (M\&C 2015), Nashville, TN, USA, April 2015.

31. J. Galloway et al., "BWR modeling capability and Scale/Triton lattice-to-core integration of the Nestle nodal simulator-331," Proceedings of PHYSOR 2010: International Conference on Advances in Reactor Physics to Power the Nuclear Renaissance, Pittsburgh, PA, USA, 2010.

32. J. D. Galloway, Boiling Water Reactor Core Simulation with Generalized Isotopic Inventory Tracking for Actinide Management, Ph.D. Dissertation, University of Tennessee, 2010. 